\title{
Comparative chloroplast genome analysis of Artemisia (Asteraceae) in East Asia: insights into evolutionary divergence and phylogenomic implications
}

Goon-Bo Kim ${ }^{1 \dagger}$, Chae Eun Lim² ${ }^{2 \dagger}$, Jin-Seok Kim², Kyeonghee Kim², Jeong Hoon Lee ${ }^{3}$, Hee-Ju Yu ${ }^{4}$ and Jeong-Hwan Mun ${ }^{1 *}$ (D)

\begin{abstract}
Background: Artemisia in East Asia includes a number of economically important taxa that are widely used for food, medicinal, and ornamental purposes. The identification of taxa, however, has been hampered by insufficient diagnostic morphological characteristics and frequent natural hybridization. Development of novel DNA markers or barcodes with sufficient resolution to resolve taxonomic issues of Artemisia in East Asia is significant challenge.

Results: To establish a molecular basis for taxonomic identification and comparative phylogenomic analysis of Artemisia, we newly determined 19 chloroplast genome (plastome) sequences of 18 Artemisia taxa in East Asia, de novo-assembled and annotated the plastomes of two taxa using publicly available Illumina reads, and compared them with 11 Artemisia plastomes reported previously. The plastomes of Artemisia were 150,858-151,318 base pairs (bp) in length and harbored 87 protein-coding genes, 37 transfer RNAs, and 8 ribosomal RNA genes in conserved order and orientation. Evolutionary analyses of whole plastomes and 80 non-redundant protein-coding genes revealed that the noncoding $\mathrm{trnH}-\mathrm{ps} b \mathrm{~A}$ spacer was highly variable in size and nucleotide sequence both between and within taxa, whereas the coding sequences of accD and ycf1 were under weak positive selection and relaxed selective constraints, respectively. Phylogenetic analysis of the whole plastomes based on maximum likelihood and Bayesian inference analyses yielded five groups of Artemisia plastomes clustered in the monophyletic subgenus Dracunculus and paraphyletic subgenus Artemisia, suggesting that the whole plastomes can be used as molecular markers to infer the chloroplast haplotypes of Artemisia taxa. Additionally, analysis of accD and ycfi hotspots enabled the development of novel markers potentially applicable across the family Asteraceae with high discriminatory power.
\end{abstract}

Conclusions: The complete sequences of the Artemisia plastomes are sufficiently polymorphic to be used as superbarcodes for this genus. It will facilitate the development of new molecular markers and study of the phylogenomic relationships of Artemisia species in the family Asteraceae.

Keywords: Artemisia, Asteraceae, Plastome, Evolution, accD, ycf1, Marker

\footnotetext{
* Correspondence: munjh@mju.ac.kr

${ }^{\dagger}$ Goon-Bo Kim and Chae Eun Lim contributed equally to this work.

'Department of Bioscience and Bioinformatics, Myongji University, Yongin

17058, Korea

Full list of author information is available at the end of the article
}

C C The Author(s). 2020 Open Access This article is licensed under a Creative Commons Attribution 4.0 International License, which permits use, sharing, adaptation, distribution and reproduction in any medium or format, as long as you give appropriate credit to the original author(s) and the source, provide a link to the Creative Commons licence, and indicate if changes were made. The images or other third party material in this article are included in the article's Creative Commons licence, unless indicated otherwise in a credit line to the material. If material is not included in the article's Creative Commons licence and your intended use is not permitted by statutory regulation or exceeds the permitted use, you will need to obtain permission directly from the copyright holder. To view a copy of this licence, visit http://creativecommons.org/licenses/by/4.0/ The Creative Commons Public Domain Dedication waiver (http://creativecommons.org/publicdomain/zero/1.0/) applies to the data made available in this article, unless otherwise stated in a credit line to the data. 


\section{Background}

The genus Artemisia L. is the largest group in the tribe Anthemideae of the family Asteraceae, consisting of approximately 500 species [1, 2]. Artemisia species are widely distributed in the temperate regions of the Northern Hemisphere, including Europe, Asia, and North America, and a few species are reported from the Southern Hemisphere [3-5]. Many Artemisia taxa have been used as food, forage, ornamental, or soil stabilizers [6]. Moreover, several Artemisia species are used as traditional medicinal herbs for their high accumulation of essential oils and terpenoids with anti-malaria, anti-cancer, and anti-diabetes effects. For instance, artemisinin isolated from $A$. annua is widely used against malaria [7].

The center of origin and diversification of the genus Artemisia is Asia [8]. In East Asia, approximately 150 Artemisia species in two subgenera (subgenus Artemisia and subgenus Dracunculus) were described from East China, Korea, and Japan [9-11], many of which are used as supplements for medicinal or health purposes. For example, dried young leaves of different Artemisia species are collectively termed as Aeyeop (A. argyi, A. montana, and $A$. princeps), Haninjin (A. gmelinii), Cheongho (A. annua and $A$. apiacea), and Injinho (A. capillaris) in Korea [12]. To establish the taxonomic delimitation and phylogenetic relationships among the Artemisia taxa, a number of classical studies based mainly on the capitula type and floret fertility have been reported describing five subgeneric or sectional groups [Artemisia, Absinthium (Miller) Less, Dracunculus (Besser) Rydb., Seriphidium Besser ex Less., and Tridentatae (Rydb.) McArthur] [1, 5, 13]. However, taxonomic classification of Artemisia species has been controversial due to the insufficient diagnostic characters, highly variable morphological traits, potential natural hybridization among taxa, polyploidy, and nomenclatural legacy [1, 5, 8, 14-16]. Meanwhile, sequencing of nuclear and organelle genome regions, such as the external and internal transcribed spacer (ETS and ITS) of nuclear ribosomal DNA $[8,16,17]$ and intergenic spacers between genes of chloroplast genome (plastome) [4, 18], has enabled molecular phylogenetic analyses of Artemisia. DNA markers widely applied to phylogenetic studies of Artemisia at the genus level include ITS, ITS2, psbA-trnH, $m a t K$, and $r b c L$. For example, the section Tridentatae, endemic to North America, was separated from the subgenus Seriphidium with strong support of ITS sequences $[16,19]$. Recently, the subgenus Pacifica, including Hawaiian species, was recognized by nuclear ribosomal (ITS and ETS) and chloroplast (trnL-F and psbA-trnH) markers [20]. However, the resolution of these markers was insufficient to resolve taxonomic issues at the species level due to high sequence similarity of closely related taxa presumably caused by rapid radiation and hybridization [21-24]. Therefore, development of novel DNA markers or barcodes for investigation of Artemisia is an important challenge.

Chloroplasts are multifunctional plant-specific organelles that carry out photosynthesis and have roles in plant growth and development, such as in nitrogen metabolism, sulfate reduction, and synthesis of starch, amino acids, fatty acids, nucleic acids, chlorophyll, and carotenoids [25]. Chloroplasts of the plant kingdom arose from a single ancestral cyanobacterium [26]. In general, the plastomes of most plants are 120-160 kilobases $(\mathrm{kb})$ in length and have a quadripartite structure comprising a large single copy (LSC), a small single copy (SSC), and two inverted repeat (IR) regions. The small and relatively constant size, conserved genome structure, and uniparental inheritance of the plastome make it an ideal genetic resource for phylogenetic analysis and molecular identification of higher plants (reviewed in [27]). Several variable regions of the plastome have been developed as DNA barcode marker systems to identify taxa. The chloroplast DNA barcode markers generated for plants include coding sequences within the plastome such as matK, ndhF, rbcL, rpoB, and rpoC1 and the intergenic regions (IGRs) between $a t p F-a t p H, p s b K-p s b I$, and trnH-psbA [28, 29]. Of particular importance is a combination of $r b c L$ and $m a t K$, which was recommended as a core barcode of land plants by the CBOL Plant Working group [28]. Additionally, $y c f 1 a$ and $y c f 1 b$ have been proposed as chloroplast barcodes due to their ease amplification by polymerase chain reaction (PCR) and abundant variations in land plants [30].

Recent advances in genome sequencing based on next generation sequencing (NGS) technologies and bioinformatics tools have increased the number of whole plastome sequences deposited in the public databases. This enables application of the plastome as a super-barcode for high-resolution phylogenetic analysis and species identification [31]. As of March 2020 (RefSeq Release 99), a total of 4718 chloroplast or plastid genomes of diverse species were deposited at the National Center for Biotechnology Information (NCBI) organelle genome database [32]. Among them, 11 plastomes of Artemisia species, A. annua L., A. argyi H. Lev. \& Vaniot, A. argyrophylla Ledeb., A. capillaris Thunberg., A. frigida Willd., A. fukudo Makino, A. gmelinii Webb ex Stechmann, $A$. montana (Nakai) Pamp., and $A$. princeps Pamp. were included (Table 1). Comparative plastome analysis of these species identified mutational hotspots from intergenic spacer regions and showed that the genus Artemisia is a monophyletic genus and is a sister to the genus Chrysanthemum [40]. Additionally, the draft nuclear genome sequence of $A$. апnua [2n $=2 \mathrm{x}=18,1.76$ gigabases $(\mathrm{Gb}) /$ $1 \mathrm{C}$ ] covering $1.74 \mathrm{~Gb}$ was reported [41]. Although few chloroplast or nuclear genomes of Artemisia species are available, they are useful resources for studies of 
Table 1 Samples and assembly statistics of the Artemisia plastomes

\begin{tabular}{|c|c|c|c|c|c|c|c|c|c|c|c|}
\hline \multirow[t]{2}{*}{ Subgenus } & \multirow[t]{2}{*}{ Section } & \multirow[t]{2}{*}{ Scientific name } & \multicolumn{4}{|c|}{ Nucleotide length (bp) } & \multicolumn{3}{|c|}{ Number of genes } & \multirow[t]{2}{*}{ Reference or Voucher ${ }^{a}$} & \multirow{2}{*}{$\begin{array}{l}\text { Genbank } \\
\text { Accession }\end{array}$} \\
\hline & & & Total & LSC & SSC & IR & Protein & tRNA & $\mathrm{rRNA}$ & & \\
\hline \multirow[t]{26}{*}{ Artemisia } & \multirow[t]{9}{*}{ Abrotanum } & A. annua & $\begin{array}{l}150 \\
952\end{array}$ & $\begin{array}{l}82 \\
772\end{array}$ & $\begin{array}{l}18 \\
268\end{array}$ & $\begin{array}{l}24 \\
956\end{array}$ & 87 & 37 & 8 & $\begin{array}{l}\text { Zhang et al. } 2017 \text { (direct } \\
\text { submission) }\end{array}$ & KY085890 \\
\hline & & A. annua & $\begin{array}{l}150 \\
955\end{array}$ & $\begin{array}{l}82 \\
776\end{array}$ & $\begin{array}{l}18 \\
267\end{array}$ & $\begin{array}{l}24 \\
956\end{array}$ & 87 & 37 & 8 & Shen et al. 2017 [33] & MF623173 \\
\hline & & A. annua & $\begin{array}{l}150 \\
955\end{array}$ & $\begin{array}{l}82 \\
776\end{array}$ & $\begin{array}{l}18 \\
267\end{array}$ & $\begin{array}{l}24 \\
956\end{array}$ & 87 & 37 & 8 & NIBRVP0000595661 & MG951482 \\
\hline & & A. apiacea & $\begin{array}{l}151 \\
091\end{array}$ & $\begin{array}{l}82, \\
830\end{array}$ & $\begin{array}{l}18 \\
343\end{array}$ & $\begin{array}{l}24 \\
959\end{array}$ & 87 & 37 & 8 & NIBRVP0000538751 & MG951483 \\
\hline & & $\begin{array}{l}\text { A. freyniana f. } \\
\text { discolor }\end{array}$ & $\begin{array}{l}151 \\
275\end{array}$ & $\begin{array}{l}82 \\
965\end{array}$ & $\begin{array}{l}18 \\
344\end{array}$ & $\begin{array}{l}24 \\
983\end{array}$ & 87 & 37 & 8 & NIBRVP0000538858 & MG951487 \\
\hline & & A. fukudo & $\begin{array}{l}151 \\
011\end{array}$ & $\begin{array}{l}82 \\
751\end{array}$ & $\begin{array}{l}18 \\
348\end{array}$ & $\begin{array}{l}24 \\
956\end{array}$ & 87 & 37 & 8 & Lee et al. 2016a [34] & KU360270 \\
\hline & & A. fukudo & $\begin{array}{l}151 \\
022\end{array}$ & $\begin{array}{l}82 \\
762\end{array}$ & $\begin{array}{l}18 \\
348\end{array}$ & $\begin{array}{l}24, \\
956\end{array}$ & 87 & 37 & 8 & NIBRVP0000597993 & MG951488 \\
\hline & & A. gmelinii & $\begin{array}{l}151 \\
247\end{array}$ & $\begin{array}{l}82 \\
988\end{array}$ & $\begin{array}{l}18 \\
341\end{array}$ & $\begin{array}{l}24 \\
959\end{array}$ & 87 & 37 & 8 & NIBRVP0000592776 & MG951489 \\
\hline & & A. gmelinii & $\begin{array}{l}151 \\
318\end{array}$ & $\begin{array}{l}83 \\
061\end{array}$ & $\begin{array}{l}18 \\
339\end{array}$ & $\begin{array}{l}24 \\
959\end{array}$ & 87 & 37 & 8 & Lee et al. 2016b [35] & NC031399 \\
\hline & \multirow[t]{4}{*}{ Absinthium } & A. frigida & $\begin{array}{l}151 \\
103\end{array}$ & $\begin{array}{l}82 \\
790\end{array}$ & $\begin{array}{l}18 \\
415\end{array}$ & $\begin{array}{l}24 \\
949\end{array}$ & 87 & 37 & 8 & SRR8208356 & n.a. \\
\hline & & A. frigida & $\begin{array}{l}151 \\
076\end{array}$ & $\begin{array}{l}82 \\
740\end{array}$ & $\begin{array}{l}18 \\
396\end{array}$ & $\begin{array}{l}24 \\
970\end{array}$ & 87 & 37 & 8 & Liu et al. 2013 [36] & NC020607 \\
\hline & & A. nakaii & $\begin{array}{l}151 \\
020\end{array}$ & $\begin{array}{l}82 \\
760\end{array}$ & $\begin{array}{l}18 \\
348\end{array}$ & $\begin{array}{l}24, \\
956\end{array}$ & 87 & 37 & 8 & NIBRVP0000598807 & MG951494 \\
\hline & & A. sieversiana & $\begin{array}{l}150 \\
910\end{array}$ & $\begin{array}{l}82 \\
710\end{array}$ & $\begin{array}{l}18 \\
304\end{array}$ & $\begin{array}{l}24 \\
948\end{array}$ & 87 & 37 & 8 & NIBRVP0000592824 & MG951499 \\
\hline & \multirow[t]{13}{*}{ Artemisia } & A. argyi & $\begin{array}{l}151 \\
176\end{array}$ & $\begin{array}{l}82 \\
915\end{array}$ & $\begin{array}{l}18 \\
347\end{array}$ & $\begin{array}{l}24 \\
957\end{array}$ & 87 & 37 & 8 & NIBRVP0000592833 & MG951484 \\
\hline & & A. argyi & $\begin{array}{l}151 \\
192\end{array}$ & $\begin{array}{l}82 \\
930\end{array}$ & $\begin{array}{l}18 \\
348\end{array}$ & $\begin{array}{l}24 \\
957\end{array}$ & 87 & 37 & 8 & Kang et al. 2016 [37] & NC030785 \\
\hline & & A. argyrophylla & $\begin{array}{l}151 \\
189\end{array}$ & $\begin{array}{l}82 \\
927\end{array}$ & $\begin{array}{l}18 \\
348\end{array}$ & $\begin{array}{l}24 \\
957\end{array}$ & 87 & 37 & 8 & Kim et al. 2017 (direct submission) & MF034022 \\
\hline & & A. feddei & $\begin{array}{l}151 \\
112\end{array}$ & $\begin{array}{l}82 \\
878\end{array}$ & $\begin{array}{l}18 \\
322\end{array}$ & $\begin{array}{l}24, \\
956\end{array}$ & 87 & 37 & 8 & NIBRVP0000592740 & MG951486 \\
\hline & & A. keiskeana & $\begin{array}{l}150 \\
858\end{array}$ & $\begin{array}{l}82 \\
622\end{array}$ & $\begin{array}{l}18 \\
344\end{array}$ & $\begin{array}{l}24 \\
946\end{array}$ & 87 & 37 & 8 & NIBRVP0000592791 & MG951492 \\
\hline & & A. montana & $\begin{array}{l}151 \\
150\end{array}$ & $\begin{array}{l}82 \\
891\end{array}$ & $\begin{array}{l}18 \\
345\end{array}$ & $\begin{array}{l}24 \\
957\end{array}$ & 87 & 37 & 8 & NIBRVP0000627850 & MG951493 \\
\hline & & A. montana & $\begin{array}{l}151 \\
130\end{array}$ & $\begin{array}{l}82 \\
873\end{array}$ & $\begin{array}{l}18 \\
343\end{array}$ & $\begin{array}{l}24 \\
957\end{array}$ & 87 & 37 & 8 & $\begin{array}{l}\text { Choi and Park, } 2014 \text { (direct } \\
\text { submission) }\end{array}$ & NC025910 \\
\hline & & A. princeps & $\begin{array}{l}151 \\
193\end{array}$ & $\begin{array}{l}82 \\
932\end{array}$ & $\begin{array}{l}18 \\
347\end{array}$ & $\begin{array}{l}24 \\
957\end{array}$ & 87 & 37 & 8 & NIBRVP0000592810 & MG951495 \\
\hline & & A. rubripes & $\begin{array}{l}151 \\
133\end{array}$ & $\begin{array}{l}82 \\
874\end{array}$ & $\begin{array}{l}18 \\
345\end{array}$ & $\begin{array}{l}24 \\
957\end{array}$ & 87 & 37 & 8 & NIBRVP0000592774 & MG951496 \\
\hline & & A. selengensis & $\begin{array}{l}151 \\
255\end{array}$ & $\begin{array}{l}82 \\
942\end{array}$ & $\begin{array}{l}18 \\
389\end{array}$ & $\begin{array}{l}24 \\
962\end{array}$ & 87 & 37 & 8 & NIBRVP0000538775 & MG951497 \\
\hline & & A. selengensis & $\begin{array}{l}151 \\
261\end{array}$ & $\begin{array}{l}82 \\
948\end{array}$ & $\begin{array}{l}18 \\
389\end{array}$ & $\begin{array}{l}24 \\
962\end{array}$ & 87 & 37 & 8 & NIBRVP0000595650 & MG951498 \\
\hline & & A. selengensis & $\begin{array}{l}151 \\
215\end{array}$ & $\begin{array}{l}82 \\
920\end{array}$ & $\begin{array}{l}18 \\
371\end{array}$ & $\begin{array}{l}24 \\
962\end{array}$ & 87 & 37 & 8 & Meng et al. 2019 [38] & MH042532 \\
\hline & & A. stolonifera & $\begin{array}{l}151 \\
144\end{array}$ & $\begin{array}{l}82 \\
878\end{array}$ & $\begin{array}{l}18 \\
350\end{array}$ & $\begin{array}{l}24 \\
958\end{array}$ & 87 & 37 & 8 & NIBRVP0000592785 & MG951500 \\
\hline
\end{tabular}


Table 1 Samples and assembly statistics of the Artemisia plastomes (Continued)

\begin{tabular}{|c|c|c|c|c|c|c|c|c|c|c|c|}
\hline \multirow[t]{2}{*}{ Subgenus } & \multirow[t]{2}{*}{ Section } & \multirow[t]{2}{*}{ Scientific name } & \multicolumn{4}{|c|}{ Nucleotide length (bp) } & \multicolumn{3}{|c|}{ Number of genes } & \multirow[t]{2}{*}{ Reference or Voucher ${ }^{\mathrm{a}}$} & \multirow{2}{*}{$\begin{array}{l}\text { Genbank } \\
\text { Accession }\end{array}$} \\
\hline & & & $\overline{\text { Total }}$ & LSC & SSC & $\mathrm{IR}$ & Protein & tRNA & $\overline{\mathrm{rRNA}}$ & & \\
\hline \multirow[t]{6}{*}{ Dracunculus } & \multirow[t]{4}{*}{ Dracunculus } & A. capillaris & $\begin{array}{l}151, \\
020\end{array}$ & $\begin{array}{l}82, \\
790\end{array}$ & $\begin{array}{l}18 \\
306\end{array}$ & $\begin{array}{l}24 \\
962\end{array}$ & 87 & 37 & 8 & Kim et al. 2017 (direct submission) & KY073391 \\
\hline & & A. capillaris & $\begin{array}{l}151 \\
020\end{array}$ & $\begin{array}{l}82 \\
790\end{array}$ & $\begin{array}{l}18 \\
306\end{array}$ & $\begin{array}{l}24 \\
962\end{array}$ & 87 & 37 & 8 & NIBRVP0000592735 & MG951485 \\
\hline & & A. capillaris & $\begin{array}{l}151 \\
056\end{array}$ & $\begin{array}{l}82 \\
821\end{array}$ & $\begin{array}{l}18 \\
313\end{array}$ & $\begin{array}{l}24 \\
961\end{array}$ & 87 & 37 & 8 & Lee et al. 2016b [35] & NC031400 \\
\hline & & A. dracunculs & $\begin{array}{l}151 \\
042\end{array}$ & $\begin{array}{l}82 \\
811\end{array}$ & $\begin{array}{l}18 \\
317\end{array}$ & $\begin{array}{l}24 \\
957\end{array}$ & 87 & 37 & 8 & SRR8208350 C & n.a. \\
\hline & \multirow[t]{2}{*}{ Latilobus } & A. hallaisanensis & $\begin{array}{l}151 \\
015\end{array}$ & $\begin{array}{l}82 \\
823\end{array}$ & $\begin{array}{l}18 \\
290\end{array}$ & $\begin{array}{l}24 \\
951\end{array}$ & 87 & 37 & 8 & NIBRVP0000538771 & MG951490 \\
\hline & & A. japonica & $\begin{array}{l}151 \\
080\end{array}$ & $\begin{array}{l}82 \\
844\end{array}$ & $\begin{array}{l}18 \\
314\end{array}$ & $\begin{array}{l}24 \\
961\end{array}$ & 87 & 37 & 8 & NIBRVP0000592828 & MG951491 \\
\hline
\end{tabular}

${ }^{a}$ Vouchers were deposited at the National Institute of Biological Resources (Incheon, Korea)

b, c Raw sequence reads were downloaded from NCBI SRA database [39] and de novo assembled in this study

Artemisia and will enable the development of a novel Artemisia DNA marker system by comparative sequence analysis.

We aimed to identify variable regions in the plastomes of the Artemisia taxa in East Asia to establish a molecular basis for the development of novel DNA barcode markers that can be widely applicable across the genus Artemisia as well as the family Asteraceae. We newly sequenced and assembled 19 plastomes of 18 taxa from two subgenera of Artemisia. Additionally, we de novoassembled and annotated two plastomes using publicly available NGS reads. Combined with 11 previously reported Artemisia plastomes, we performed a comparative analysis of 32 Artemisia plastomes and identified highly variable regions in the Artemisia plastomes. Our results provide a robust genomic framework for taxonomic and phylogenomic characterization of Artemisia species in East Asia and the development of DNA markers that allow identification of individual taxa in a cost-effective manner.

\section{Results}

\section{Structure and features of the Artemisia plastomes}

A total of 32 complete plastomes from 21 Artemisia taxa were analyzed (Table 1). These taxa belong to the sections Abrotanum, Absinthium, and Artemisia of the subgenus Artemisia and the sections Dracunculus and Latilobus of the subgenus Dracunculus [5, 6, 11]. Among them, 19 plastomes from 18 taxa were newly sequenced and assembled in this study. To assemble the plastomes, we generated approximately 35.2 million Illumina MiSeq PE reads $(10.6 \mathrm{~Gb})$ on average per sample (Additional file 2: Table $\mathrm{S} 1$ ). De novo assembly of the Illumina reads using $r b c L$ and rpoC2 of $A$. argyi (GenBank accession NC030785) as seed sequences resulted in the construction of a circular DNA sequence map for each sample. Additionally, the Sequence Read Archive (SRA) reads of $A$. dracunculus
(SRR8208350) and A. frigida (SRR8208356) deposited in NCBI were de novo assembled into circular plastomes. The 21 de novo-assembled plastomes were verified by mapping of sequence reads affording 666-fold average coverage (296-fold to 1187-fold coverage). The remaining 11 plastomes from 9 Artemisia species were downloaded from NCBI. The structural orientation of the LSC, SSC, and IR regions of each assembly was analyzed by comparison with previously reported Artemisia plastomes. As a result, we obtained at least two independent plastome assemblies for each of eight species (A. annua, A. argyi, $A$. capillaris, A. frigida, A. fukudo, A. gmelinii, A. montana, and $A$. selengensis) and a single plastome for each of 13 taxa (A. apiacea, A. argyrophylla, A. dracunculus, A. feddei, A. freyniana $f$. discolor, A. hallaisanensis, A. japonica, A. keiskeana, A. nakaii, A. princeps, A. rubripes, A. sieversiana, and $A$. stolonifera).

The de novo-assembled Artemisia plastomes were 150, 858 bp (A. keiskeana) to 151,318 bp (A. freyniana $f$. discolor) in length with a $37.4-37.5 \%$ GC content, similar to previously reported Artemisia plastomes. They had a typical quadripartite structure consisting of $82,622-82,988 \mathrm{bp}$ of LSC, 24,946-24,983 bp of SSC, and a pair of IRs, each of which was 18,267-18,389 bp (Fig. 1). Comparing with the plastome of Nicotiana tabacum (GenBank accession NC001879), all the Artemisia plastomes had two inversions (approximately $22 \mathrm{~kb}$ and $3.3 \mathrm{~kb}$ in length) in the LSC region that have been reported to be shared by all clades of the Asteraceae family (Fig. 1) [42]. Gene annotation showed that the Artemisia plastomes contained 87 protein-coding genes, 37 transfer RNAs (tRNAs), and 8 ribosomal RNA (rRNA) genes in conserved order and orientation (Table 1). Comparison of plastome sequences from the same species, except $A$. capillaris (GenBank accession KY073391 and MG951485), identified three bp (A. annua) to $71 \mathrm{bp}$ (A. frigida) length differences that are randomly distributed both in genic and non-genic regions. 


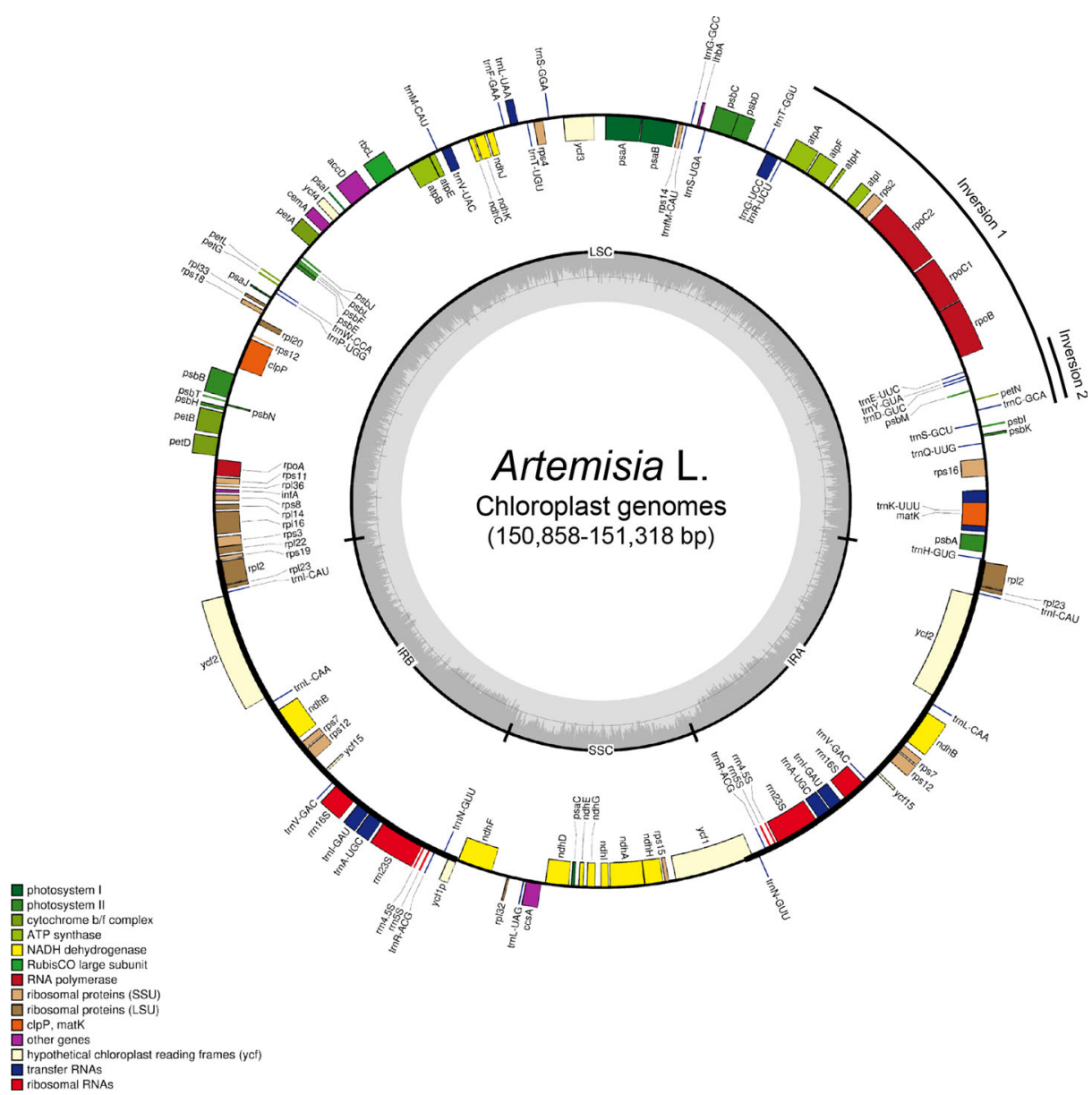

Fig. 1 A circular gene map of the Artemisia plastomes. Circle 1 (from inside) indicates the GC content. The colored bars on circle 2 indicate protein-coding genes, tRNA genes, and rRNA genes. Genes are placed on the inside or outside of circle 2 according to their orientations. Functional categories of genes are presented in the left margin. IR, inverted repeat region; LSC, large single copy region; SSC, small single copy region

In every Artemisia plastome, the junctions between IRs and LSC and SSC were flanked by rps19 and $y c f 1$, respectively (Additional file 1: Fig. S1). The IR border structure was conserved in Artemisia, except A. selengensis in which three independent plastomes have seven bp expansion in rps19 at the LSC/IR and SSC/IR junctions. In addition, unlike the reports of Meng et al. [38] and Shen et al. [33], 4rps19 was located at the IRb/LSC junction in all Artemisia plastomes. Seven protein-coding genes ( $n d h B, r p l 2$, $r p l 23, r p s 7, r p s 12, y c f 2$, and $y c f 15$ ), four rRNA genes, and seven tRNA genes were duplicated in the two IRs. Moreover, 12 protein-coding genes and six tRNA genes had one or two introns (Additional file 2: Table S2). Of the total plastomes, protein-coding genes comprised 52.3\% whereas rRNA and tRNA genes accounted for 6.0 and $1.9 \%$, respectively. We found several annotation errors in the previously reported sequences. For example, two pseudogenes, $\psi y c f 1$ and $\psi r p s 19$, were newly identified in all of the plastomes and $p s b G$ in $A$. annua (GenBank accession MF623173) was an erroneous annotation.

\section{Identification of polymorphisms in the Artemisia plastomes}

A sequence comparison of 32 Artemisia whole plastomes generated multiple aligned sequences of $153,229 \mathrm{bp}$ in length. The alignment exhibited high pairwise sequence identities between plastomes of the same section, ranging from 99.2\% (section Absinthium) to 99.8\% (section Dracunculus) in whole plastomes and from 99.7\% (section Absinthium) to $99.9 \%$ (section Dracunculus) in the protein-coding genes. Interestingly, the protein-coding genes of A. argyrophylla (GenBank accession MF034022) in section Artemisia and A. nakaii (GenBank accession MG951494) in section Absinthium showed 100\% identity with those of $A$. argyi (GenBank accessions MG951484 and NC030785) in section Artemisia and A. fukudo 
(GenBank accessions KU360270 and MG951488) in section Abrotanum, respectively (Additional file 2: Table S3).

A total of 2172 variable sites comprising 1062 singleton variable sites and 1110 parsimony informative (PI) sites $(0.72 \%)$ were identified across the whole plastome alignment (Table 2). The overall nucleotide diversity $(\pi)$ was 0.0024; however, each structural region of plastome showed different nucleotide diversities and PI sites; these were highest in SSC $(\pi=0.0047$ and $\mathrm{PI}=1.37 \%)$ and lowest in IR $(\pi=0.0006$ and PI $=0.19 \%)$ regions. Based on DNA polymorphisms, the Artemisia plastomes could be divided into 30 chloroplast haplotypes along with 30 LSC, 26 SSC, and 23 IR haplotypes. Across the Artemisia plastomes, highly diverged regions were identified by calculating $\pi$ values within $1 \mathrm{~kb}$ sliding windows with 100 bp steps (Fig. 2). In total, 11 peaks with $\pi$ values higher than 0.006 were identified from the plastome. These regions included trnH-psbA, rps16, rps16-trnQUUG, trnE-UUC-rpoB, ndhC-trnV-UAC, rbcL-accD, and $a c c D$ in LSC and ndhF-rpl32, rpl32-trnL-UAG, rps15$y c f 1$, and $y c f 1$ in SSC regions (Additional file 2: Table S4 and S5). Sequence analysis of three highly diverged protein-coding genes $(a c c D, y c f 1$, and rps16) revealed high polymorphisms $(\pi>0.006)$ in the coding sequences of $a c c D$ and $y c f 1$ and in the intron of rps16.

For 80 non-redundant protein-coding genes, a total of $68,062 \mathrm{bp}$ sequences were multiply aligned. The overall nucleotide diversity of protein-coding genes $(\pi=0.0015)$ was approximately 1.6-fold lower than that of whole plastome $(\pi=0.0024)$. Notably, 17 genes had a higher $\pi$ than the overall $\pi$ value and showed an average $99.5 \%$ pairwise sequence similarity of coding sequences (Table 3). The PI sites of these genes comprised $39.2 \%$ (144 of 367 sites) of the total PI sites in all protein-coding genes. Of particular interest, $a c c D$, encoding the beta-carboxyl transferase subunit of acetyl-CoA carboxylase, and $y c f 1$, encoding Tic214 of the TIC complex, showed lower sequence identity, higher nucleotide diversity, and a larger number of PI sites than the other genes, indicating a high level of sequence divergence. Additionally, $n d h F$ and rpoC2 had more than ten PI sites; however, their $\pi$ values were lower than 0.003 . Therefore, two protein-coding genes, $a c c D$ and $y c f 1$, were identified as nucleotide diversity hotspots of the Artemisia chloroplast protein-coding genes, and have potential as candidate regions for the development of universal barcode markers.

\section{Variation and evolutionary selection of protein-coding genes}

No gene loss was detected from the 32 Artemisia plastomes; however, single nucleotide insertion or deletion (InDel) mutations resulting in a premature stop codon were found in rpoA of $A$. montana (GenBank accession MG951493) and $y c f 1$ of $A$. selengensis (GenBank accession MH042532), respectively. The frameshift caused by single nucleotide InDels generated truncated coding sequences, $816 \mathrm{bp}$ instead of $1009 \mathrm{bp}$ for rpoA of $A$. montana and $1290 \mathrm{bp}$ rather than $5033 \mathrm{bp}$ for $y c f 1$ of $A$. selengensis. In $A$. sieversiana (GenBank accession MG951499), one SNP in $n d h I$ induces an in-frame premature stop codon, resulting in loss of eight codons at the 3 '-end of the open reading frame.

Synonymous (Ks) and non-synonymous substitution rates (Ka) are useful for inferring the evolutionary tendency of genes. To evaluate differences in the selection and evolution of protein-coding genes in the Artemisia plastomes, the nucleotide substitution rates and average $\mathrm{Ka} / \mathrm{Ks}$ ratio $(\omega)$ of 17 highly divergent genes were calculated. As shown in Table 3 and Fig. 3, 15 genes exhibited $\omega$ values less than 0.5 , suggesting the action of high selective constraints or purifying selection. In contrast, the $\omega$ for $y c f 1$ and $a c c D$ was 0.67 and 1.06, respectively, suggesting that these genes are under relaxed selective constraints and weak positive selection, respectively. These results are consistent with reports that most genes in the Artemisia plastome evolve under negative selection; however, $a c c D$ is under positive selection [38, 44]. The likelihood ratio test of the site-specific model in CodeML program validated the evolutionary selection patterns of $a c c D$ and $y c f 1$. The Bayes empirical Bayes (BEB) identified 8 amino acid sites from $a c c D$ and $y c f 1$, respectively, that were positively selected under posterior probability $>0.95$ (Additional file 2: Table S6). In $a c c D$, six out of the eight positively selected amino acid

Table 2 DNA polymorphisms identified in the 32 Artemisia plastomes

\begin{tabular}{|c|c|c|c|c|c|c|c|}
\hline \multirow{2}{*}{$\begin{array}{l}\text { Structural } \\
\text { region }\end{array}$} & \multirow{2}{*}{$\begin{array}{l}\text { Alignment } \\
\text { length (bp) }\end{array}$} & \multicolumn{3}{|c|}{ Number of variable sites } & \multicolumn{3}{|c|}{ Nucleotide polymorphism } \\
\hline & & Polymorphic & Singleton & $\mathrm{Pl}^{\mathrm{a}}$ & PI sites (\%) & $\pi^{\mathrm{b}}$ & $\mathrm{H}^{c}$ \\
\hline Whole DNA & 153,229 & 2172 & 1062 & 1110 & 0.72 & 0.0024 & 30 \\
\hline LSC & 84,443 & 1501 & 742 & 759 & 0.90 & 0.0029 & 30 \\
\hline SSC & 18,737 & 523 & 266 & 257 & 1.37 & 0.0047 & 26 \\
\hline $\mathbb{R}^{d}$ & 50,049 & 148 & 54 & 94 & 0.19 & 0.0006 & 23 \\
\hline
\end{tabular}

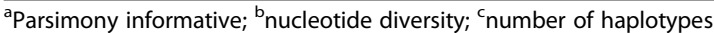

${ }^{\mathrm{d}}$ Alignments of two IR regions were combined and the $7 \mathrm{bp}$ expansion in $A$. selengensis was included 


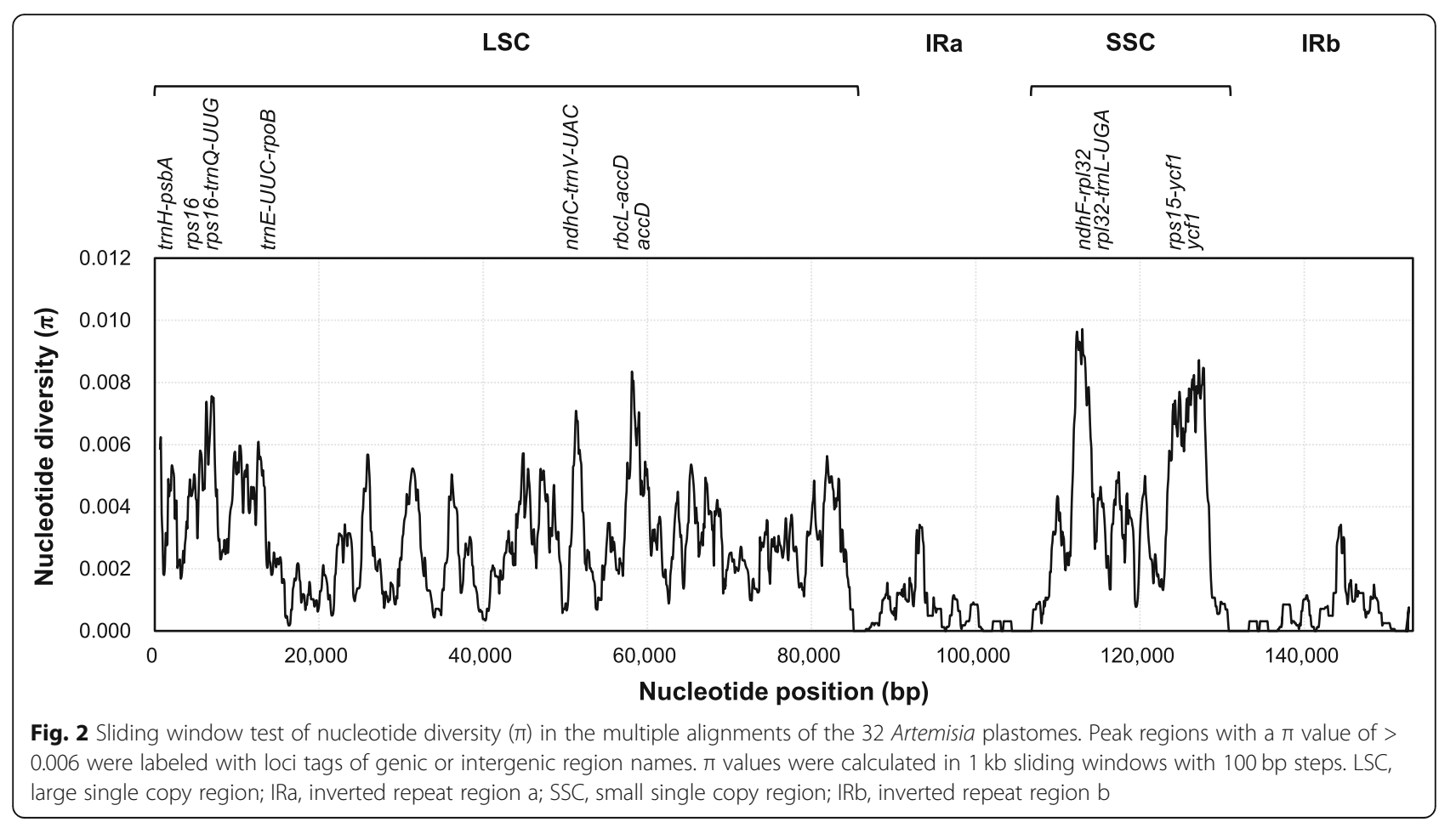

Table 3 Evolutionary characteristics of 17 highly diverged protein-coding genes in the Artemisia plastome

\begin{tabular}{|c|c|c|c|c|c|c|c|c|c|}
\hline Gene $^{a}$ & Length of alignment (bp) & Avg. pairwise similarity (\%) & Identical sites (\%) & $\pi$ & $\mathrm{H}$ & Total variable sites & Singleton sites & PI sites & $\overline{\mathrm{Ka} / \mathrm{Ks}^{\mathrm{c}}}$ \\
\hline$\overline{y c f 1}$ & 5076 & 98.96 & 94.2 & 0.0065 & 24 & 44 & 21 & 23 & 0.6674 \\
\hline$a c c D$ & 1572 & 98.7 & 92.8 & 0.0057 & 19 & 42 & 12 & 30 & 1.0568 \\
\hline $\inf A$ & 231 & 99.63 & 97.9 & 0.0037 & 7 & 5 & 2 & 3 & 0.0097 \\
\hline ndhE & 303 & 99.63 & 98.4 & 0.0036 & 6 & 5 & 2 & 3 & 0.0295 \\
\hline rps8 & 402 & 99.67 & 98.5 & 0.0033 & 7 & 6 & 1 & 5 & 0.3830 \\
\hline$n d h F$ & 2223 & 99.7 & 98.5 & 0.0030 & 18 & 32 & 9 & 23 & 0.1783 \\
\hline psac & 243 & 99.71 & 98.4 & 0.0029 & 5 & 4 & 2 & 2 & 0 \\
\hline petD & 480 & 99.71 & 98.3 & 0.0029 & 8 & 8 & 4 & 4 & 0.0112 \\
\hline rp/22 & 471 & 99.66 & 97.3 & 0.0027 & 9 & 7 & 3 & 4 & 0.1161 \\
\hline$p s b T$ & 99 & 99.76 & 97.1 & 0.0025 & 4 & 3 & 3 & 0 & 0 \\
\hline rp/16 & 405 & 99.73 & 98.8 & 0.0022 & 6 & 5 & 1 & 4 & 0 \\
\hline rp/36 & 111 & 99.8 & 98.2 & 0.0020 & 2 & 2 & 0 & 2 & 0 \\
\hline matk & 1515 & 99.52 & 97.6 & 0.0019 & 16 & 20 & 11 & 9 & 0.2803 \\
\hline rps3 & 654 & 99.69 & 98.3 & 0.0018 & 12 & 11 & 4 & 7 & 0.1808 \\
\hline psbK & 177 & 99.67 & 98.9 & 0.0017 & 3 & 2 & 1 & 1 & 0.1924 \\
\hline rpoc2 & 4137 & 99.8 & 98.5 & 0.0017 & 22 & 56 & 36 & 20 & 0.3194 \\
\hline petB & 645 & 99.78 & 98.8 & 0.0016 & 9 & 8 & 4 & 4 & 0 \\
\hline Overall & 68,214 & 99.50 & 98.2 & 0.0015 & 28 & 769 & 402 & 367 & 0.1774 \\
\hline
\end{tabular}

${ }^{a}$ Genes with $>0.2 \%$ average pairwise dissimilarity and $>0.0015 \pi$ values were selected

${ }^{\mathrm{b} C}$ oding sequences were aligned using MUSCLE and translational alignment in Geneious Prime

${ }^{c} \mathrm{Ka} / \mathrm{Ks}$ values $(\omega)$ were calculated according to Yang and Nielsen (2000) [43] using the yn00 program in the PAML 4 package 


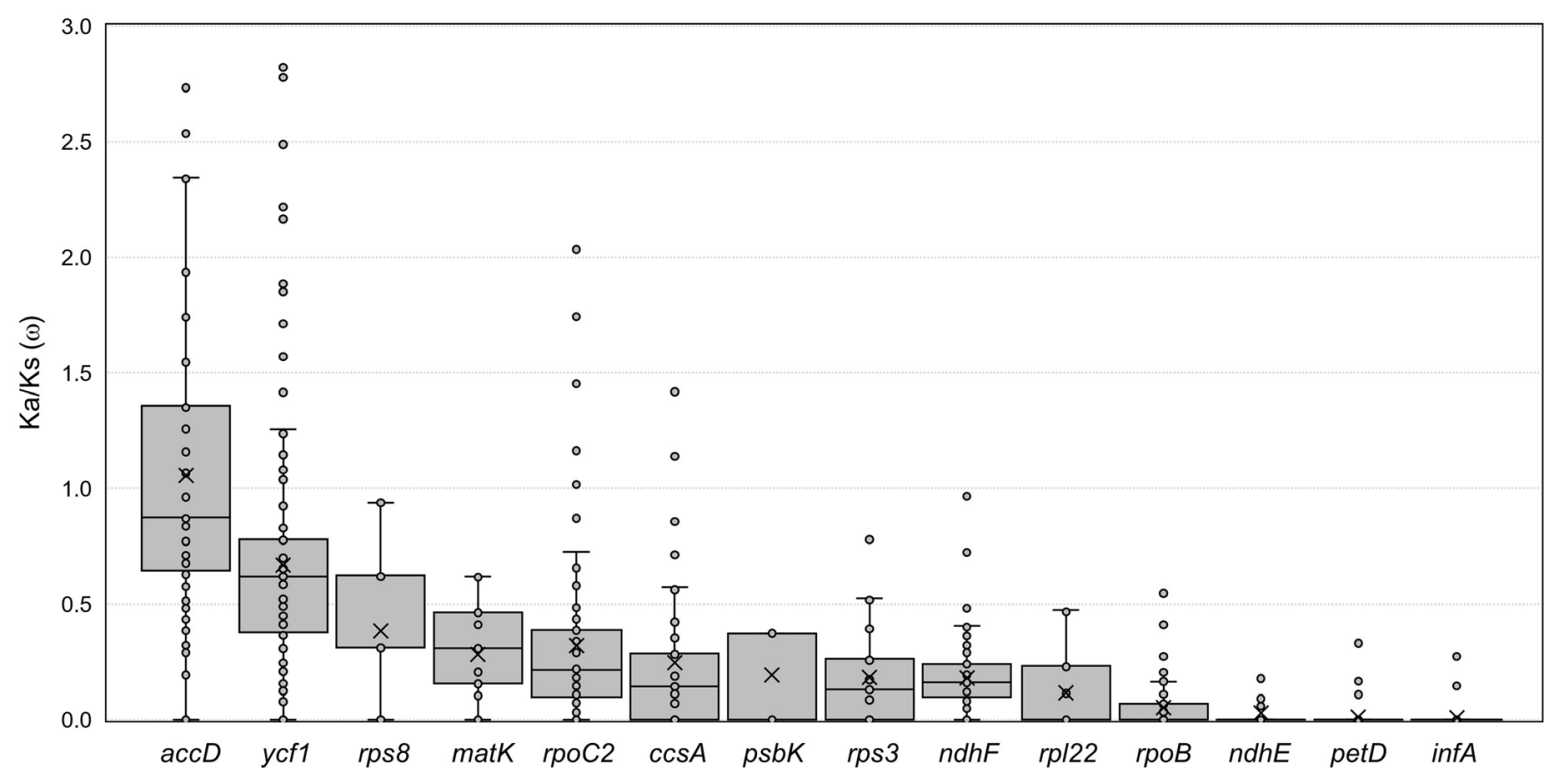

Fig. 3 Box-and-whisker plots of the Ka/Ks $(\omega)$ values of highly diverged protein-coding genes in the Artemisia plastomes. The pairwise $\omega$ values of 14 protein-coding genes in the 32 Artemisia plastomes were calculated and plotted. Box plots show the median (central line), mean ( $\times$ symbol), first and third quartiles (top and bottom bars), and outliers

substitutions were located near A. selengensis-specific insertions consisting of 6 codon sequences repeating three or four times (Additional file 1: Fig. S2). This region is a polymorphic hotspot of $a c c D$. In contrast, the positively selected amino acid substitutions in $y c f 1$ were widely distributed across the coding sequences.

\section{Repetitive sequences in the Artemisia plastomes}

Repeated DNA sequences in the plastome play a role in genome rearrangement and are useful for phylogenetic studies. We investigated simple sequence repeats (SSRs) and long sequence repeats (LSRs) in the multiple alignment of the 32 Artemisia whole plastomes (Table 4 and Fig. 4). A total of 431 SSR loci of short (2-6 bp) nucleotide motifs were discovered. Approximately 39.0\% (168 of 431 loci) of SSR loci were in the protein-coding sequences. Moreover, only 27 SSR loci $(6.2 \%)$ were polymorphic across the 32 plastomes; all were located in LSC and SSC, but none in IR, regions. In the Artemisia plastomes, di- and trinucleotide repeats were the most frequent, accounting for 72.2 and $18.4 \%$ of the total SSRs, respectively (Fig. 4a).

A total of 94 LSRs were identified (Fig. 4b). Unlikely SSRs, more than half of them (55.3\%) were polymorphic (Table 4). Among the polymorphic LSRs, those repeated twice (38 of 49) were most abundant. Palindromic and hairpin repeats were also found. LSRs were 2.3-fold as frequent in IGRs compared to genic regions. In each structural region, SSC region had the highest average density of LSRs per kilobase $(1.4 / \mathrm{kb})$, followed by LSC $(1.2 / \mathrm{kb})$ and IR $(0.8 / \mathrm{kb})$ regions. Most repeat units were less than $15 \mathrm{bp}$ in length, which accounted for $81 \%$ of the total LSRs (Additional file 2: Table S7).

\section{Phylogenetic analysis and delimitation of the Artemisia plastomes}

Using 80 protein-coding genes and the complete plastome sequences, we performed phylogenetic analyses of the 32 Artemisia plastomes. The topology of the maximum likelihood (ML) and Bayesian inference (BI) trees based on protein-coding genes was nearly identical (Fig. 5 and Additional file 1: Fig. S3). Additionally, no significant differences between the trees in protein-coding genes and whole plastomes were found, except clustering of A sieversiana (MG951499). The analyses discriminated 19 of 21 (90.5\%) analyzed plastomes and divided the Artemisia plastomes into five clades of two subgenera. The subgenus level classification of Artemisia based on plastomes was in agreement to the previous studies inferred from different types of DNA markers [4, 8, 16, 18, 19, 45]. The plastomes of the subgenus Dracunculus clustered together in monophyletic clade VI whereas those of the subgenus Artemisia were clustered into four paraphyletic clades (clades I - III and V). In contrast, plastomes in the same section were divided into different clades, showing that the previous section level classifications of Artemisia species $[5,6,11,17]$ were weakly supported by the plastome trees. All plastomes from the same species clustered together. Moreover, most plastomes of different taxa were distinct, except $A$. argyi, A. argyrophylla, and $A$. princeps, which clustered together in clade I with a near-zero branch length. These three 
Table 4 Simple sequence repeats and long sequence repeats identified in the 32 Artemisia plastomes

\begin{tabular}{|c|c|c|c|c|c|c|c|c|c|}
\hline \multicolumn{2}{|l|}{ Repeats } & \multicolumn{4}{|l|}{ SSR } & \multicolumn{4}{|l|}{ LSR } \\
\hline Structural reg & & LSC & SSC & $\mathrm{IR}$ & Total & LSC & SSC & IR & Total \\
\hline \multirow[t]{3}{*}{ Numbers } & Overall & 296 & 60 & 75 & 431 & 62 & 22 & 10 & 94 \\
\hline & Polymorphic & 22 & 5 & 0 & 27 & 37 & 12 & 3 & 52 \\
\hline & Monomorphic & 274 & 55 & 75 & 404 & 25 & 10 & 7 & 42 \\
\hline \multirow[t]{3}{*}{ Genic region } & CDS & 109 & 25 & 34 & 168 & 10 & 7 & 2 & 19 \\
\hline & Intron & 39 & 5 & 10 & 54 & 3 & 2 & 0 & 5 \\
\hline & $\mathrm{rRNA} / \mathrm{tRNA}$ & 8 & 0 & 9 & 17 & 0 & 0 & 0 & 0 \\
\hline \multicolumn{2}{|c|}{ Intergenic region } & 140 & 30 & 22 & 192 & 49 & 13 & 8 & 70 \\
\hline
\end{tabular}

species showed 99.97-99.99\% sequence similarity to the whole plastome (Additional file 2: Table S3). Similarly, A. nakaii clustered with $A$. fukudo as expected from the plastome sequence similarity (99.99\%). This finding supports the hypothesis that a number of $A$. nakaii accessions are likely to be interspecific hybrid taxa and its maternal origin might be A. fukudo [46].

Molecular markers for Artemisia and the Asteraceae species A comparative sequence analysis revealed that $a c c D$ and $y c f 1$ are highly polymorphic in the Artemisia plastomes; therefore, these genes have potential for the development of Artemisia molecular markers. For $a c c D$, the $928 \mathrm{bp}$ un-gapped alignment of the $1 \mathrm{~kb}$ region flanking the polymorphic hotspot was investigated as a molecular marker. For $y c f 1$, we evaluated the potential utility of the Asteraceae $y c f 1$ locus by reconstructing a phylogenetic tree based on the coding sequences of 211 $y c f 1$ genes from Asteraceae whole plastomes in the NCBI nucleotide database. A ML tree constructed using the $y c f 1$ genes showed that the Asteraceae species were divided into nine groups; in agreement with the tribe level taxonomic classification of the Asteraceae (Additional file 1: Fig. S4) [47-49]. The topology of a ML tree
A

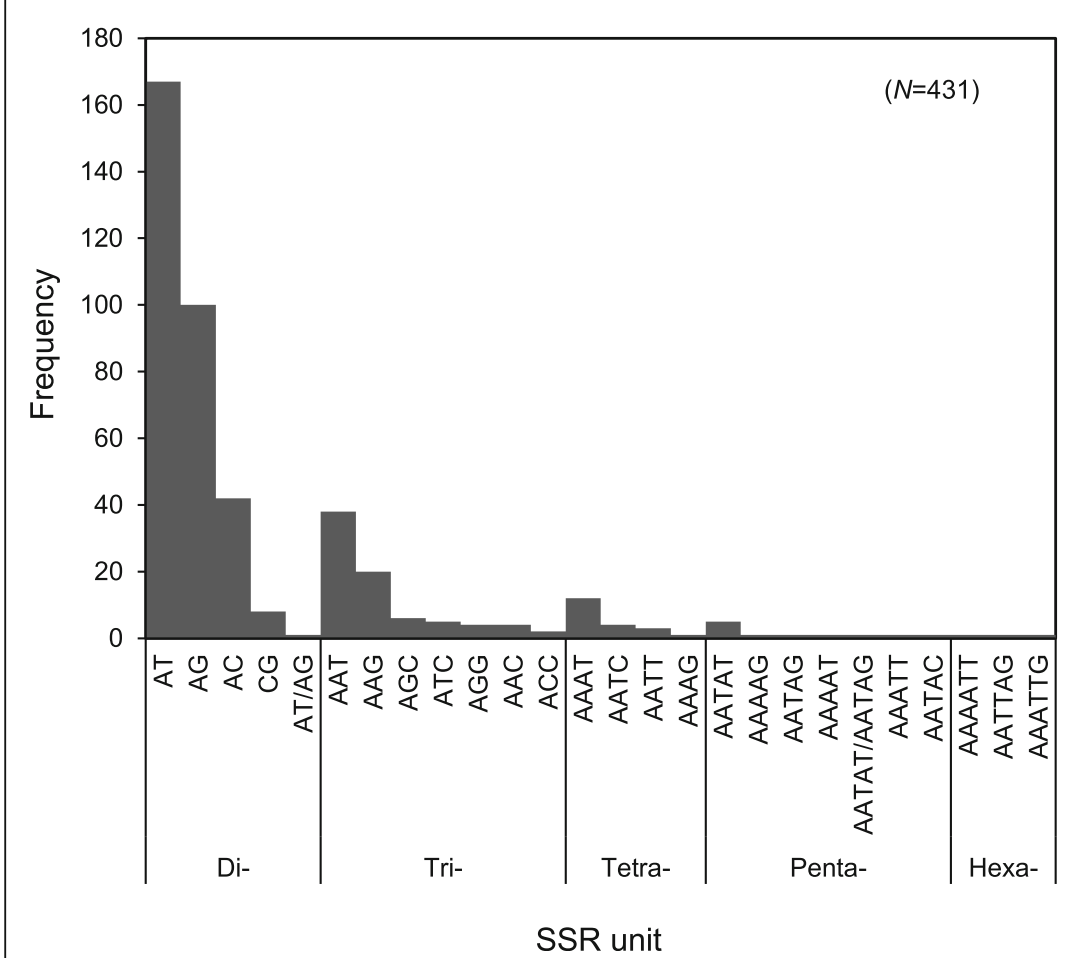

B

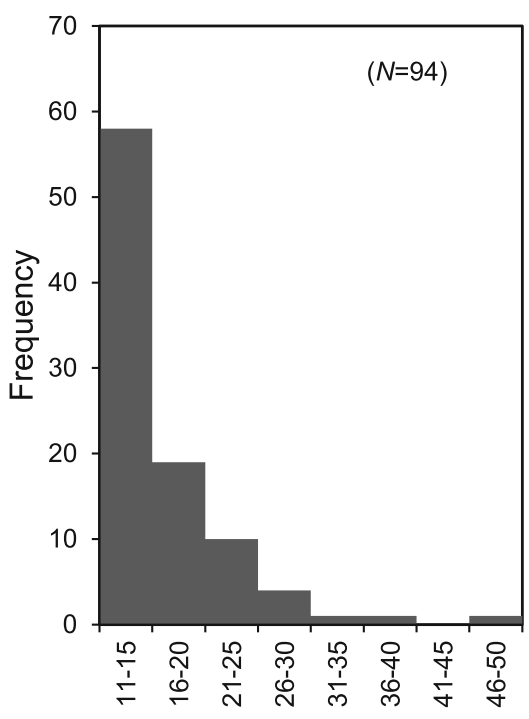

LSR unit (bp)

Fig. 4 Frequency of repetitive sequences in the Artemisia plastomes. a Frequency of SSRs with di- to hexa-nucleotide motifs. $\mathbf{b}$ Frequency of LSRs with 11-50 nucleotide repeat units 


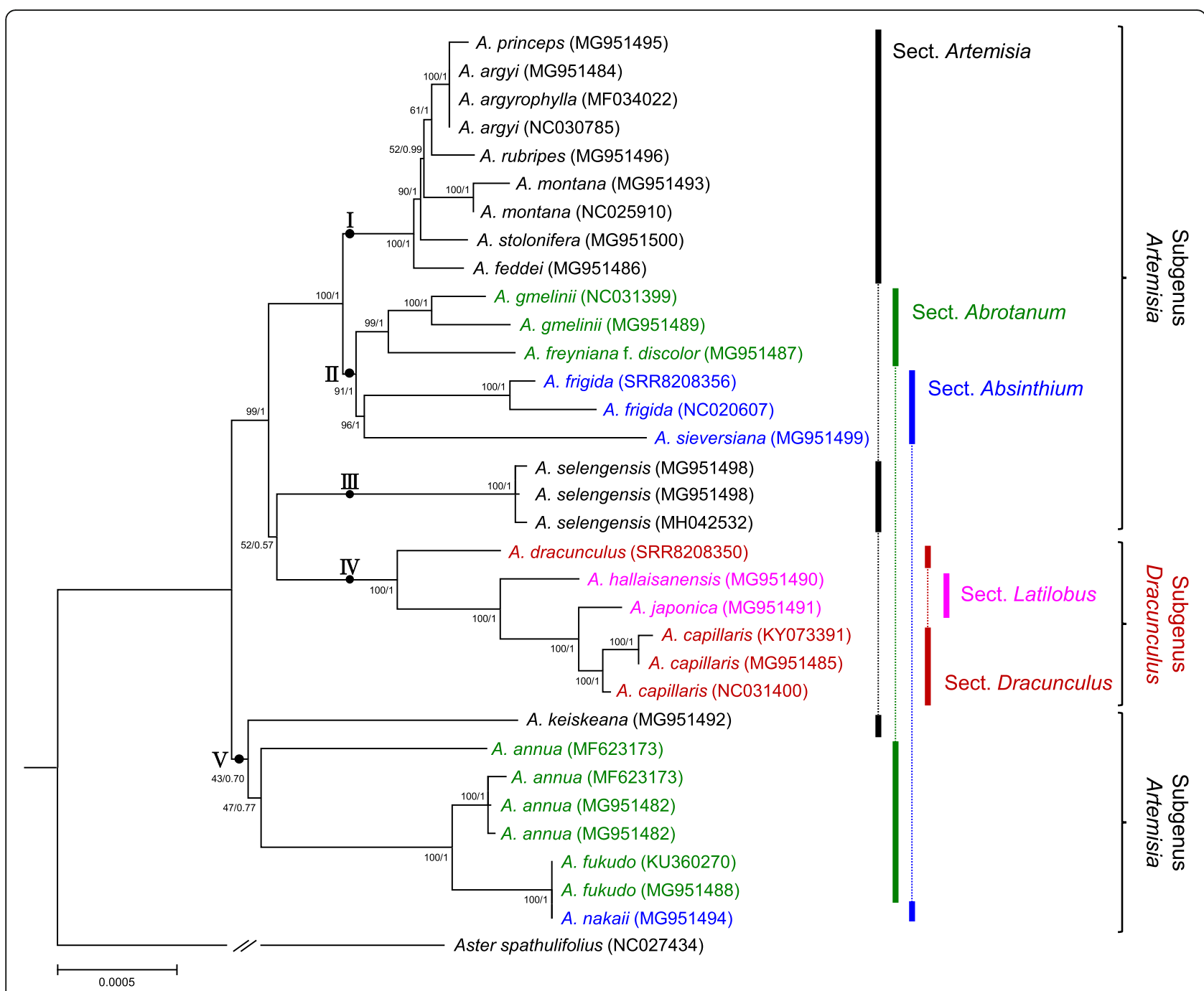

Fig. 5 Phylogenetic tree of Artemisia taxa based on 80 non-redundant protein-coding genes of the plastome. BI tree topology is shown and BI posterior probability/ML bootstrap values are indicated on the nodes. Branch lengths were estimated by BI analysis. Colored lines and braces at the right of the tree indicate section and subgenus names of Artemisia

Table 5 Nucleotide diversity and discriminatory power of the Artemisia chloroplast markers

\begin{tabular}{|c|c|c|c|c|c|}
\hline$\overline{\text { Loci }}$ & $\operatorname{trnH}-p s b A$ & accD-hotspot & $y c f 1 b$ & $a c c D-1 k$ & $y c f 1 b+a c c D-1 k$ \\
\hline Length (bp) & 357 & 276 & 847 & 928 & 1775 \\
\hline Number of sequence & 32 & 32 & 32 & 32 & 32 \\
\hline Number of haplotype & 18 & 11 & 18 & 19 & 21 \\
\hline Haplotype diversity & 0.952 & 0.985 & 0.951 & 0.962 & 0.970 \\
\hline$\pi$ & 0.0137 & 0.0219 & 0.0080 & 0.0077 & 0.0080 \\
\hline Polymorphic site & 25 & 23 & 38 & 47 & 52 \\
\hline PI site & 15 & 9 & 21 & 36 & 33 \\
\hline Singleton site & 10 & 1 & 17 & 11 & 19 \\
\hline
\end{tabular}


based on 212 Asteraceae $a c c D$ genes was similar (Additional file 1: Fig. S5). However, the resolution was insufficient for species delimitation. BLAST search of $a c c D$ and $y c f 1$ against the Asteraceae plastomes revealed that these genes have higher tribe resolution $(83.4 \%$ for $a c c D$ and $99.1 \%$ for $y c f 1)$ than species resolution $(42.4 \%$ for $a c c D$ and 62.2 for $y c f 1$ ). (Additional file 1: Fig. S6).

To develop Artemisia molecular markers with increased resolution of phylogeny reconstruction, we tested the combination of $a c c D$ and $y c f 1 b$, a candidate plastid barcode for land plants developed based on the $y c f 1$ hotspot [30]. The $a c c D$ marker is 928 bp in length ( $a c c D-1 \mathrm{k}$ ) and discriminated 19 Artemisia haplotypes (nucleotide diversity, $\pi=0.0077$ ). Similarly, $y c f 1 b$ is $847 \mathrm{bp}$ in length and discriminated 18 haplotypes $(\pi=0.0080)$. The combination of $a c c D$ and $y c f 1 b(a c c D-1 \mathrm{k}+y c f 1 b)$ increased the discriminatory power of the marker; 21 haplotypes were distinguished $(\pi=0.0080)$ (Table 5$)$. The topology of the ML tree based on $a c c D-1 \mathrm{k}+y c f 1 b$ was similar to that of whole plastomes (Additional file 1: Fig. S7).

To optimize the $a c c D-1 \mathrm{k}+y c f 1 b$ marker for the family Asteraceae, $212 a c c D$ and $211 y c f 1$ genes of Asteraceae species retrieved from NCBI were analyzed. We compared the primer binding sites using multiple aligned sequences of each gene under a $95 \%$ threshold of consensus. The Asteraceae $y c f 1$ sequences at the 3 '-end of the ycflbF primer binding site [30] had five to six nucleotide mismatches. In contrast, the primer binding sites of ycf1bR as well as of the forward and reverse primers of $a c c D-1 \mathrm{k}$ were mostly conserved. Considering the consensus sequences, we designed and optimized primer pairs of the $a c c D-1 \mathrm{k}+y c f 1 b$ marker for Asteraceae species (Table 6). In silico estimation of PCR amplification under two stringency criteria predicted a $96-100 \%$ PCR success rate for the ycflb-Asteraceae-F/R primer pair in the Asteraceae family (Additional file 2: Table S8) compared to $0 \%$ for the $y c f 1 b F / R$ primer pair [30]. The accD-Asteraceae-F/R primer pair was predicted to have a $100 \%$ PCR success rate under both stringency conditions.

\section{Discussion}

The accurate identification of plant species is important not only for taxonomy but also in agriculture and pharmaceuticals. The genus Artemisia includes a number of taxa of medicinal and economic value; however, classification and delimitation of individual species are challenging due to the insufficient morphological characters, frequent natural hybridization, and the presence of diverse intermediates [1, 5, 14-16]. Molecular marker techniques based on robust genomic tools could resolve issues in the species delimitation and phylogenetic relationships of Artemisia. As a universal barcode for plants, ITS1, ITS2, and ETS were developed into a sequence-characterized amplified region $[50,51]$ or high-resolution melt markers [52] and applied to Artemisia. However, insufficient sequence polymorphism of the markers and the frequent polyploidy of Artemisia hindered their use for species identification. In the previous comparative plastome analysis of the 11 Artemisia species, intergenic spacer regions, including $c c s A-n d h D$, trnHpsbA, ndhG-ndhI, rps18-rpl20, and rps15-ycf1, were identified as mutational hotspots. However, these loci have not been analyzed in the wide range of taxa of the Asteraceae family [40]. Additionally, known core chloroplast barcodes, such as $r b c L$, mat $K, r p o B$ and rpoC1, had low discriminatory power for classification of Artemisia taxa [21-23]. Therefore, discovery of novel barcodes with high discriminatory power or use

Table 6 Optimized $\operatorname{accD}$ and ycf1 barcode primers for the family Asteraceae

\begin{tabular}{|c|c|c|c|}
\hline \multirow{2}{*}{$\frac{\text { Barcode }}{\text { accD-1 k }}$} & \multicolumn{2}{|l|}{ Primer } & \multirow{2}{*}{$\begin{array}{l}\text { Sequence }\left(5^{\prime} \text { to } 3^{\prime}\right) \\
\text { CGATGTTATTTAAGAMGGAGTTCG }\end{array}$} \\
\hline & Forward & Consensus at 95\% threshold ${ }^{a}$ & \\
\hline & & accD-Asteraceae- $\mathrm{F}^{\mathrm{b}}$ & CGATGTTATTTAAGAAGGAGTTCG \\
\hline & Reverse & Consensus at $95 \%$ threshold ${ }^{a}$ & CAAACGGGTAATTTTCTCCCC \\
\hline & & accD-Asteraceae- $\mathrm{R}^{\mathrm{b}}$ & CAAACGGGTAATTTTCTCCCC \\
\hline & Expected & & $928-1079$ \\
\hline \multirow[t]{7}{*}{ ycfib } & Forward & Consensus at $95 \%$ threshold ${ }^{d}$ & RMTCGACGAAAATCYGGTTCTTCYAAAT \\
\hline & & ycf1b-Asteraceae- $F^{c}$ & GCTCGACGAAAATCCGGTTCTTCCAAAT \\
\hline & & $y c f 1 b F^{e}$ & TCTCGACGAAAATCAGATTGTTGTGAAT \\
\hline & Reverse & Consensus at 95\% threshold ${ }^{d}$ & WTACATGYSAAAGTGATGGAAAA \\
\hline & & ycf1b-Asteraceae- $R^{c}$ & ATACATGCCAAAGTGATGGAAAA \\
\hline & & $y c f 1 b R^{e}$ & ATACATGTCAAAGTGATGGAAAA \\
\hline & \multicolumn{2}{|c|}{ Expected amplicon size (bp) } & 874 \\
\hline
\end{tabular}

\footnotetext{
${ }^{a}$ Consensus at $95 \%$ threshold across 212 accD sequences from the family Asteraceae

b, cOptimized primers for the family Asteraceae

${ }^{d}$ Consensus at $95 \%$ threshold across 211 ycf1 sequences from the family Asteraceae

eUniversal barcode primer set designed for angiosperm [30]
} 
of the whole plastome as a super-barcode is important. In this study, we investigated 32 whole plastomes from 21 Artemisia taxa native to East Asia, the largest number of Artemisia plastomes analyzed to date, to establish a basis for phylogenomics and DNA barcode development.

The Artemisia plastomes showed structural characteristics and genetic properties typical of the angiosperm plastome. The plastomes of Artemisia taxa are approximately $151 \mathrm{~kb}$ in length on average and organized into quadripartite regions with no structural variation among taxa. Each genome contains the same number of genes (87 protein-coding, 37 tRNA, and 8 rRNA genes) with a similar GC content and conserved intron positions. Such highly similar plastomes of Artemisia taxa enable multiple alignment of protein-coding genes and whole plastomes to identify regions with high sequence divergence. Interestingly, singly nucleotide InDel mutations resulting in frame-shift or premature stop codon were identified in rpoA of $A$. montana and $y c f 1$ of $A$. selengensis. In several species of Asteraceae, similar single nucleotide InDels were identified at the SSC/IR junction. For example, both Chrysanthemum indicum (GenBank accession NC020320) and C. boreal (GenBank accession MG913594) harbor a single nucleotide InDel in $y c f 1$, which leads to a premature stop codon. A comparative sequence analysis identified eight IGRs with relatively high sequence divergence between taxa, mostly due to insertion of LSRs. In particular, trnH-psbA has been used as a plant DNA barcode [53]. The noncoding trnH$p s b A$ spacer of Artemisia contains LSRs highly variable in size and sequence between and even within species, providing sufficient discriminatory power $(\pi=0.014)$ for taxon delimitation. Additionally, we identified highly diverged intergenic regions in the Artemisia plastome, such as rps16-trnQ-UUG, trnE-UUC-rpoB, ndhC-trnV-UAC, and $r b c L-a c c D$ in LSC and ndhF-rpl32, rpl32-trnL-UAG, and rps15-ycf1 in SSC. These regions have sufficient potential to be used as barcode markers (Additional file 2, Table S5). We anticipate that successful PCR amplification of these intergenic spacers and other polymorphic LSR loci will enable development of a single DNA marker for genotype identification below the species level. Meanwhile, consistent with a report of selected chloroplast genes in a limited number of Artemisia species in China [21], most protein-coding genes had low sequence divergence, with the exception of $a c c D, y c f 1$, and $r p s 16$. These genes contained nucleotide diversity hotspots in exon ( $a c c D$ and $y c f 1$ ) or intron (rps16) regions that were under weak positive selection or relaxed selective constraints. $a c c D$ was reported to be under positive selection $(\omega>1)$ in A. selengensis [38] whereas the 5 '-region of the $y c f 1$-coding sequence was suggested to be a plastid barcode for land plants [30]. These two genes play important roles in flowering plants. Plastid $a c c D$ and $y c f 1$ are essential for plant fitness and leaf development [54] or viability [55]. Interestingly, $a c c D$ genes in several angiosperm lineages, such as Campanulaceae and Poaceae, were lost or relocated to the nuclear genome, presumably due to endosymbiotic evolution [56]. Because the highly variable nucleotide sequences of $a c c D$ and $y c f 1$ in a range of land plants are likely to be the result of environmental adaptation during evolution [57-59], they may be useful markers for plastid evolution. In this study, the conserved coding sequences flanking variable regions of $a c c D$ and $y c f 1$ in Artemisia enabled the design of PCR primers for crossspecies amplification with clear sequence polymorphisms, yielding novel Artemisia barcode markers with sufficient resolution to distinguish $18(y c f 1 b), 19$ (accD-1 k), and 21 $(a c c D-1 \mathrm{k}+y c f 1 b)$ plastome haplotypes from 21 Artemisia taxa (Table 5). This is the highest discriminatory power of chloroplast markers to identify chloroplast haplotype reported from Artemisia to date. Moreover, we described the utilization of $a c c D$ and $y c f 1$ as molecular markers for phylogenetic analysis of the Asteraceae family. As shown in the ML tree based on 211 Asteraceae $y c f 1$ sequences, $y c f 1$ enabled tribe level resolution of the family Asteraceae (Additional file 1: Fig. S4). Phylogenetic analysis based on $a c c D$ resulted in an ML tree showing similar topology, which enabled separation of all tribes in the family Asteraceae (Additional file 1: Fig. S5). Indeed, nucleotide sequence divergence in $a c c D$ was concentrated in a small hotspot (Additional file 1: Fig. S2); therefore, this hotspot could serve as a universal marker for the family Asteraceae. The $y c f 1 b$ marker, which was designed based on the consensus sequence of 144 species of 16 families [30], had a number of nucleotide mismatches in the primer binding sites for diverse Asteraceae $y c f 1$ genes. We designed and optimized novel primer sets for the $y c f 1$ and $a c c D$ markers to ensure amplification of all Asteraceae species. Importantly, the combination of $a c c D$ and $y c f 1$ has potential as a core molecular marker for Asteraceae based on its increased resolution for taxon delimitation of Artemisia.

Phylogenetic inference based on molecular markers that have evolved under strong pressures of natural selection would be untrustworthy [60]. According to the $\mathrm{Ka} / \mathrm{Ks}$ ratio, $\operatorname{accD}(\omega=1.06)$ and $y c f 1(\omega=0.67)$ are assumed to have evolved under relaxation of selective constraints. Additionally, their reconstructed topologies were congruent with those inferred from different types of markers. These findings suggest that the use of $a c c D$ and $y c f 1$ markers on phylogeny estimation can be potentially effective. Another strength of this study is the use of whole plastome sequences as well as 80 proteincoding genes as super-barcodes for phylogenomic inference of Artemisia based on maternal haplotypes. Recent progress in whole genome sequencing of $A$. аnnua [41] and analyses of conserved orthologs in the Asteraceae 
$[61,62]$ expanded our understanding of taxonomic relationships among Artemisia species based on the nuclear genome. Meanwhile, the chloroplast DNA markers developed in this study provide straightforward tools to infer evolutionary changes in the maternal lineages. The comparative analysis of complete plastome sequences and 80 protein-coding genes as super-barcodes in Artemisia discriminated the plastomes of most taxa and strongly supported the subgenus level classification, enabling higher-resolution analysis of relationship among taxa than prior phylogenetic studies using nuclear ITS/ ETS or selected chloroplast DNA data $[4,8]$. There was no difference in the tree topology between the ML and BI analyses and there was robust support for most clades, suggesting the validity of the relationships among clades and taxa (Fig. 5 and Additional file 1: Fig. S3). Interestingly, both phylogenetic trees strongly supported (100\%) the monophyletic group of the subgenus Dracunculus consisting of $A$. capillaris, A. dracunculus, and $A$. hallaisanensis, whereas the subgenus Artemisia was paraphyletic with two divided clades. This finding was consistent with the previous molecular phylogenetic studies reporting that the subgenus Dracunculus was a monophyletic group and the subgnus Artemisia was a paraphyletic group $[8,16,19]$. In contrast, the traditional section level classification of Artemisia taxa [5, 6, 11, 17] had no support from clades based on the whole plastomes. A new finding is putative introgressive hybridizations between members of $A$. argyi/A. argyrophylla/A. princeps and $A$. fukudo/A. nakaii. The almost identical whole plastome sequences and sympatric distribution of these taxa suggest on-going hybridization among members of these taxa. Introgressive hybridization, combined with rapid radiation, may have caused the transfer of chloroplast haplotypes between species which might account for the inconsistency between traditional section level classification and plastome phylogeny. Molecular markers developed from nuclear genome should provide additional information to distinguish those taxa harboring the same plastome and to create reliable phylogenies of the genus Artemisia.

\section{Conclusions}

The whole plastome including 80 protein-coding genes of Artemisia is sufficiently polymorphic to be used as super-barcodes for this genus, although they did not show $100 \%$ discriminatory power. In addition, $a c c D$ and $y c f 1$ are highly polymorphic loci not only in Artemisia but also in the family Asteraceae; therefore, these genes have potential as universal markers for the family Asteraceae. The complete plastome investigated in this study will facilitate further research on Artemisia and will enhance our understanding of Asteraceae plastome evolution.

\section{Methods}

\section{Plant materials and DNA extraction}

A total of 19 individual samples representing 18 taxa of the genus Artemisia (A. апnua, A. apiacea, A. argyi, A. capillaris, A. feddei, A. freyniana f. discolor, A. fukudo, A. gmelinii, A. hallaisanensis, A. japonica, A. keiskeana, A. montana, A. nakaii, A. princeps, $A$. rubripes, $A$. selengensis, $A$. sieversiana, and $A$. stolonifera) were collected in Korea. We achieved all required permits for the protected areas from the National Park Services and local governments. For $A$. selengensis, two independent samples were included. After species identification based on morphological characters, the voucher specimens were preserved in the herbarium $(\mathrm{KB})$ of the National Institute of Biological Resources (Incheon, Korea). Details of the plant samples are presented in Table 1. Genomic DNAs were extracted from the dried leaves using a cetyl trimethylammonium bromide method [63] with modifications of polysaccharide precipitation by 2-propanol in the presence of $2.5 \mathrm{M} \mathrm{NaCl}$ and RNase treatment.

\section{Sequencing, assembly, and annotation}

Illumina sequencing libraries with $500 \mathrm{bp}$ inserts for 19 samples were constructed using the TruSeq DNA PCRFree kit (Illumina, San Diego, CA, USA) and paired-end (PE) sequences $(2 \times 300 \mathrm{bp})$ were generated using the MiSeq platform (Illumina). The sequence data generated in this study are summarized in Additional file 2: Table S1. Additionally, Illumina reads of $A$. frigida (NCBI SRR8208356) and $A$. dracunculus (NCBI SRR8208350) were downloaded from the NCBI SRA database and were subjected to the downstream analysis. To assemble the sequence reads from each library into a circular plastome, NOVOPlasty software v2.6.6 [64] was used with $r b c L$ and $r p o C 2$ chosen from the published plastome of A. argyi (GenBank accession NC030785) as seed sequences. With the draft assemblies, orientation of the SSC was determined according to its structural order in the plastome of $A$. argyi and the completeness of each assembly was verified by read mapping using Geneious Prime v2019 (Biomatters, Auckland, New Zealand) [65]. Any ambiguous regions in the draft assembles were subjected to Sanger sequencing of PCR amplicons. Genes in the plastomes were identified using Geneious Prime with a $90 \%$ similarity criterion compared to the published $\mathrm{Ar}$ temisia plastomes with subsequent manual curation. tRNA genes were identified with tRNAscan-SE software [66]. All identified genes were validated by comparison with the homologs in the Arabidopsis thaliana plastome (GenBank accession AP000423). Circular gene maps of the Artemisia plastomes were generated using OGDRAW v.1.2 [67]. The plastome sequences of $11 \mathrm{Ar}$ temisia species deposited in GenBank were downloaded and re-annotated as described above. The plastomes 
assembled in this study have been deposited in NCBI under the accession numbers MG951482 - MG951500.

\section{Sequence comparison and divergence analysis}

Whole plastomes of 32 Artemisia samples were aligned using MAFFT v7.450 [68]. Additionally, the nucleotide sequences of 80 non-redundant protein-coding genes were extracted from each plastome, concatenated into a single sequence, and aligned using the Translation Alignment tool with MAFFT in Geneious Prime. After removing gaps and poorly aligned regions using the Mask Alignment tool of Geneious Prime, the pairwise distance of 80 protein-coding genes between taxa was calculated with Geneious Prime. For each gene, multiple sequence alignment was obtained using the Translation Alignment tool with MUSCLE [69] in Geneious Prime with default options. Individual alignments were manually curated. Nucleotide diversity (average number of nucleotide differences per site between two sequences, $\pi$ ), number of variable sites, and PI sites were obtained using DnaSP v6 [70]. Chloroplast DNA inversions in the Artemisia plastomes were identified using the Mauve tool of Geneious Prime and the plastome sequence of Nicotiana tabacum (GenBank accession NC001879) as a reference. $\mathrm{Ka}$ and $\mathrm{Ks}$ values of the coding sequences were determined using the yn00 program in the PAML v4.9i package [71]. To identify positively selected sites in multiple sequence alignments, site models (seqtype $=1$, model $=0$, NSsites $=0,1,2,3,7,8)$ in CodeML from PAML v4.9i or EasyCodeML v1.21 [72] were used. The unrooted ML tree of 32 Artemisia taxa, constructed using the MAFFT alignments of 80 protein-coding genes and RAxML v8.2.9 [73], was used as an input tree. The amino acid sites under positive selection were detected based on the results of a posterior BEB analysis with a probability threshold of 0.95 . SSRs with a unit length of 2-6 bp repeated at least three times were surveyed across the 32 Artemisia whole plastomes using Phobos v3.3.12 in Geneious Prime. LSRs were identified using Repeat Finder v1.0.1 in Geneious Prime and their structures and inter-taxon polymorphisms were manually curated. LSR was defined as $11-100 \mathrm{bp}$ with spacers no longer than $50 \mathrm{bp}$ and $100 \%$ identity between sequences. Both direct tandem and hairpin repeats were considered, and palindromic structures were analyzed. LSRs located in SSR regions were excluded to reduce redundancy.

\section{Phylogenetic analysis}

Phylogenetic trees based on 80 protein-coding genes of 32 Artemisia plastomes were generated by the ML and BI methods using RAxML v8.2.9 [73] and MrBayes v3.2.7 [74], respectively, with Aster spathulifolius (GenBank accession NC027434) as an outgroup. For ML analysis, partitioning of protein-coding genes was carried out using PartitionFinder2 with a greedy algorithm [75] and unlinked branchlengths parameter. The GTR $+\mathrm{G}$ model for protein-coding genes and the GRT + G+I model for whole plastomes was chosen as the best-fit DNA substitution model according to the Akaike Information Criterion correction in ModelTest-NG v0.1.6 [76]. ML trees were constructed using rapid bootstrapping and search for the best-scoring ML tree option of RAxML v8.2.9 [73] with 1000 bootstrap replicates. To choose appropriate outgroup taxa, the species from several tribes of the Asteraceae, including Cynara humilis in Cardueae, Helianthus annuus in Helentheae, Aster spathulifolius in Astereae, and Chrysanthemun boreale and $C$. indicum in Anthemideae, were analyzed together with Artemisia taxa. Among them, A. spathulifolius (GenBank accession NC027434) was chosen as an outgroup species due to its distinct separation from the ingroup taxa. For Bayesian analysis, the Markov chain Monte Carlo (MCMC) algorithm was applied for 11 million generations with four heated chains and sampling of trees every 1000 generations. The first $25 \%$ of trees were discarded as burn-in. The average standard deviation of split frequencies was below 0.01 after 800,000 generations and 0.0028 at the final generation. The Potential Scale Reduction Factor, a convergence diagnostic, was 1.001 on average. The posterior distribution was evaluated using Tracer v1.7 [77]. On the trace plot of log-likelihood, a good sign of MCMC convergence was shown before $10 \%$ proportion of burn-in. The consensus trees were finally edited using the MEGA7 software [78].

\section{Development of Asteraceae markers}

Complete plastomes of Asteraceae species were downloaded from NCBI non-redundant DNA database. In the case of redundant sequences available for the same accession, further analysis collapsed them into one representative plastome. The coding sequences of $a c c D$ and $y c f 1$ from 219 plastomes, identified using BLASTN (BLAST+ v2.10.0) search, were extracted and aligned using MUSCLE [69]. Sequences shorter than $1 \mathrm{~kb}$ for $a c c D$ and $1.5 \mathrm{~kb}$ for $y c f 1$ were excluded. The sequence alignments of $212 a c c D$ and $211 y c f 1$ genes were further refined by translation align in Geneious Prime. For the combinations of these two genes, aligned sequences of $a c c D$ and $y c f 1$ were concatenated. A phylogenetic tree of Asteraceae $a c c D$ and $y c f 1$ was constructed by the ML method using RAxML software with the GTRGAMMA model and 1000 bootstrap replications. The barcode PCR primers were manually designed based on the consensus sequences generated from the multiple sequence alignments at a threshold level of $95 \%$. In silico PCR analysis was conducted using FastPCR software v6.0 [79]. 


\section{Supplementary information}

Supplementary information accompanies this paper at https://doi.org/10. 1186/s12864-020-06812-7.

Additional file 1 : Figure S1 to S7. Fig. S1. Comparison of the IR border regions of the Asteraceae plastomes. Fig. S2. Multiple alignments of accD coding sequences in the 32 Artemisia plastomes showing hotspots of nucleotide sequence diversity. Eight positively selected amino acid substitutions are indicated by red triangles. The core hotspot of $276 \mathrm{bp}$ in length (616-963 bp over the gapped alignment) is indicated by arrows. Fig. S3. A ML tree based on the whole plastomes of 32 Artemisia taxa. Bootstrap values are indicated on the nodes. Colored lines and braces at the right of the tree indicate section and subgenus names of Artemisia, respectively, that include taxa. Fig. S4. A ML tree of ycf1 in the Asteraceae family. Taxa belonging to the same supertribe or subfamily are grouped. Fig. S5. A ML tree of accD in the Asteraceae family. Taxa belonging to the same supertribe or subfamily are grouped. Fig. S6. Performances of $a c c D$ and $y c f 1$ in identifying the Asteraceae taxa using BLAST search. Hits with $100 \%$ identity were counted into two categories, unique hit and cross-hit to other species or tribe(s). Fig. S7. A $\mathrm{ML}$ tree based on the $a c c D-1 \mathrm{k}+y c f 1 b$ marker sequences of 32 Artemisia taxa. Bootstrap values are indicated on the nodes.

Additional file $\mathbf{2}$ : Tables $\mathbf{S 1}$ to $\mathbf{5 8}$. Table $\mathbf{S 1}$. Sample information and statistics of the Illumina PE sequence data of Artemisia taxa. Table S2. Gene contents of the Artemisia plastomes. Table S3. Pairwise nucleotide similarity matrix of the 32 Artemisia plastomes. Table S4. Highly variable regions among the 32 Artemisia plastomes. Table S5. Nucleotide diversity and polymorphism of 11 highly diverged regions in the Artemisia plastome. Table S6. Likelihood ratio tests to identify positively selected sites within the $a c c D$ and ycfl coding sequences across the 32 Artemisia plastomes. Table S7. Polymorphic LSRs identified in the 32 Artemisia plastomes. Table S8. In silico PCR analysis of the accDAsteraceae and ycf1b-Asteraceae markers.

\section{Abbreviations}

BEB: Bayes empirical Bayes; BI: Bayesian Inference; bp: base pairs; ETS: External transcribed spacer; Gb: Gigabases; IGR: Intergenic region; InDel: Insertion or deletion; IR: Inverted repeat; ITS: Internal transcribed spacer; Ka: Nonsynonymous substitution rate; kb: kilobases; Ks: Synonymous substitution rate; LSC: Long single copy; LSR: Long sequence repeat; MCMC: Markov chain Monte Carlo; ML: Maximum likelihood; NCBI: National Center for Biotechnology Information; NGS: Next generation sequencing; $\omega$ : Ka/Ks; п: nucleotide diversity; PCR: Polymerase chain reaction; PI: Parsimony informative; rRNA: ribosomal RNA; SRA: Sequence Read Archive; SSC: Short single copy; SSR: Simple sequence repeat; tRNA: transfer RNA

\section{Acknowledgments}

Authors appreciate parataxonomists of The Society for Korean Peninsula Plants (SKPP) who helped collecting Artemisia samples from Korea. We also thank to Jung-Hyun Kim and Se-A Ryu of NIBR for supporting studies of Artemisia and preparing voucher specimens.

\section{Authors' contributions}

JHM planned the projects, designed the research, analyzed data, and wrote the manuscript. GBK and CEL performed the experiments, analyzed data, and wrote the manuscript. JSK, KK, and JHL performed the experiments. HJY participated in data analysis and manuscript preparation. All authors have read and approved the manuscript.

\section{Funding}

This work was supported by grants from the National Institute of Biological Resources (NIBR201922101), the Next-Generation Biogreen21 program (PJ013194), Rural Development Administration, Korea, and the Myongji University Research Year Grant (2020). The funding bodies played no role in the design of the study and collection, analysis, and interpretation of data and in writing the manuscript.

\section{Availability of data and materials}

The assembled sequences described in this study have been deposited in the National Center for Biotechnology and Information (NCBI) under the accessions as summarized in Table 1.

\section{Ethics approval and consent to participate}

Not applicable.

\section{Consent for publication}

Not applicable.

\section{Competing interests}

The authors declare that they have no competing interests.

\section{Author details}

${ }^{1}$ Department of Bioscience and Bioinformatics, Myongji University, Yongin 17058, Korea. ${ }^{2}$ National Institute of Biological Resources, Incheon 22689, Korea. ${ }^{3}$ Department of Herbal Crop Research, National Institute of Horticultural and Herbal Science, Chungbuk 27709, Korea. ${ }^{4}$ Department of Life Science, the Catholic University of Korea, Bucheon 14662, Korea.

Received: 20 February 2020 Accepted: 8 June 2020

Published online: 22 June 2020

\section{References}

1. Bremer K, Humphries C. Generic monograph of the Asteraceaeanthemideae. Bull Nat His Mus. 1993;23:71-177.

2. Heywood V, Humphries C. Anthemideae - systematic review. In: Heywood V, Humphries C, Turner B, editors. The Biology and Chemistry of the Compositae. London: Academic Press; 1977

3. Oberprieler C, Himmelreich S, Källersjö M, Vallès J, Watson L, Vogt R. Anthemideae. In: Funk V, Susanna A, Steussy T, Bayer R, editors. Systematics, Evolution, and Biogeography of Compositae. Vienna: International Association for Plant Taxonomy; 2009. p. 631-66.

4. Riggins C, Seigler D. The genus Artemisia (Asteraceae: anthemideae) at a continental crossroads: molecular insights into migrations, disjunctions, and reticulations among old and New World species from a Beringian perspective. Mol Phylogenet Evol. 2012;64:471-90.

5. Vallès J, Garcia S, Hidalgo O, Martín J, Pellicer J, Sanz M, Garnatje T. Biology, Genome Evolution, Biotechnological Issues and Research Including Applied Perspectives in Artemisia (Asteraceae). In: Kader J, Delseny M, editors. Advances in Botanical Research Vol 60, vol. 60. London: Academic Press; 2011. p. 349-419.

6. Vallès J, McArthur E. Artemisia systematics and phylogeny: Cytogenetic and molecular insights, USDA Forest Service Proceedings RMRS-P-21; 2001. p. $67-74$.

7. Duffy PE, Mutabingwa TK. Artemisinin combination therapies. Lancet. 2006; 367:2037-9.

8. Sanz M, Vilatersana R, Hidalgo O, Garcia-Jacas N, Susanna A, Schneeweiss G, Vallès J. Molecular phylogeny and evolution of floral characters of Artemisia and allies (anthemideae, Asteraceae): evidence from nrDNA ETS and ITS sequences. Taxon. 2008:57:66-78.

9. Hu S. The Compositae of China, vol. 18. Taipei: Taiwan Museum; 1965.

10. Koyama H. Artemisia. In: Flora of Japan, vol. Illb. Tokyo: Kodansha; 1993.

11. Park M. A systematic study of the genus Artemisia (Asteraceae) in Korea [doctoral thesis]. Andong: Andong National University; 2012.

12. Sung J, Lee J, JWL, Bang B, Yeo J, Park C, Park H, Seong N, Moon S. Phylogenetic analysis of Artemisia spp. by morphological characteristics of reproductive organs in Korea. Korean J Medicinal Crop Sci. 2008;16:218-24.

13. Ling Y. The old world Artemsia Linn. (Compositae). Bull Bot Res. 1992:12:1-108.

14. McArthur E, Welch B, Sanderson S. Natural and artificial hybridization between big sagebrush (Artemisia tridentata) subspecies. J Hered. 1988;79: $268-76$

15. Richardson B, Page J, Bajgain P, Sanderson S, Udall J. Deep sequencing of amplicons reveals widespread intraspecific hybridization and multiple origins of polyploidy in big sagebrush (Artemisia tridentata; Asteraceae). Am Bot. 2012:99:1962-75.

16. Watson L, Bates P, Evans T, Unwin M, Estes J. Molecular phylogeny of subtribe Artemisiinae (Asteraceae), including Artemisia and its allied and segregate genera. BMC Evol Biol. 2002;2:17. 
17. Vallès J, Torrell M, Garnatje T, Garcia-Jacas N, Vilatersana R, Susanna A. The genus Artemisia and ITS allies: phylogeny of the subtribe Artemisiinae (Asteraceae, anthemideae) based on nucleotide sequences of nuclear ribosomal DNA internal transcribed spacers (ITS). Plant Biol. 2003;5:274-84.

18. Pellicer J, Vallès J, Korobkov A, Garnatje T. Phylogenetic relationships of Artemisia subg. Dracunculus (Asteraceae) based on ribosomal and chloroplast DNA sequences. Taxon. 2011;60:691-704

19. Torrell M, Garcia-Jacas N, Susanna A, Vallès J. Phylogeny in Artemisia (Asteraceae, anthemideae) inferred from nuclear ribosomal DNA (ITS) sequences. Taxon. 1999;48:721-36.

20. Hobbs C, Baldwin B. Asian origin and upslope migration of Hawaiian Artemisia (Compositae-anthemideae). J Biogeogr. 2013;40:442-54.

21. Liu G, Ning H, Ayidaerhan N, Aisa H. Evaluation of DNA barcode candidates for the discrimination of Artemisia L. Mitochondrial DNA A. 2017;28:956-64.

22. Mei Q, Chen X, Xiang L, Liu Y, Su Y, Gao Y, Dai W, Dong P, Chen S. DNA barcode for identifying folium Artemisiae argyi from counterfeits. Bio Pharm Bull. 2016:39:1531-7.

23. Wang $X-Y$, Zheng S-H, Liu Y, Han J-P. ITS2, a better DNA barcode than ITS in identification of species in Artemisia L. Chin Herb Med. 2016;8:352-8.

24. Garcia S, Canela M, Garnatje T, McArthur E, Pellicer J, Sanderson S, Valles J. Evolutionary and ecological implications of genome size in the north American endemic sagebrushes and allies (Artemisia, Asteraceae). Biol J Linn Soc. 2008;94:631-49.

25. Jensen $P$, Leister D. Chloroplast evolution, structure and functions. F1000Prime Rep. 2014;6:40

26. Miyagishima S. Origin and evolution of the chloroplast division machinery. J Plant Res. 2005;118:295-306.

27. Wicke S, Schneeweiss G, dePamphilis C, Müller K, Quandt D. The evolution of the plastid chromosome in land plants: gene content, gene order, gene function. Plant Mol Biol. 2011;76:273-97.

28. CBOL Plant Working Group. A DNA barcode for land plants. Proc Natl Acad Sci U S A. 2009;106:12794-7.

29. Pennisi E. Taxonomy. Wanted: a barcode for plants. Science. 2007;318:190-1.

30. Dong W, Xu C, Li C, Sun J, Zuo Y, Shi S, Cheng T, Guo J, Zhou S. ycf1, the most promising plastid DNA barcode of land plants. Sci Rep. 2015;5:8348.

31. Li $X$, Yang $Y$, Henry R, Rossetto $M$, Wang $Y$, Chen S. Plant DNA barcoding: from gene to genome. Biol Rev Camb Philos Soc. 2015;90:157-66.

32. The National Center for Biotechnology Information organelle genome database. www.ncbi.nlm.nih.gov/genome/organelle. Accessed 1 June 2019.

33. Shen X, Wu M, Liao B, Liu Z, Bai R, Xiao S, Li X, Zhang B, Xu J, Chen S. Complete chloroplast genome sequence and phylogenetic analysis of the medicinal plant Artemisia annua. Molecules. 2017;22:1330.

34. Lee Y, Park J, Kim J-K, Lee H, Park H-S, Lee S-C, Kang J, Lee T, Sung S, Yang T-J. Complete chloroplast genome sequence of Artemisia fukudo Makino (Asteraceae). Mitochondrial DNA B. 2016;1:376-7.

35. Lee Y, Park J, Kim J-K, Lee H, Park H-S, Lee S-C, Kang J, Lee T, Sung S, Yang T-J. The complete chloroplast genome sequences of Artemisia gmelinii and Artemisia capillaris (Asteraceae). Mitochondrial DNA B. 2016;1:410-1.

36. Liu Y, Huo N, Dong L, Wang Y, Zhang S, Young H, Feng X, Gu Y. Complete chloroplast genome sequences of Mongolia medicine Artemisia frigida and phylogenetic relationships with other plants. PLoS One. 2013;8:e57533.

37. Kang S-H, Kim K, Lee J-H, Ahn B, Won S, Sohn S-H, Kim J. The complete chloroplast genome sequence of medicinal plant, Artemisia argyi. Mitochondrial DNA B. 2016;1:257-8.

38. Meng D, Xiaomei Z, Wenzhen $\mathrm{K}, \mathrm{Xu} Z$ Z. Detecting useful genetic markers and reconstructing the phylogeny of an important medicinal resource plant, Artemisia selengensis, based on chloroplast genomics. PLoS One. 2019;14: e0211340.

39. The National Center for Biotechnology Information SRA database. www. ncbi.nlm.nih.gov/sra. Accessed 1 June 2019

40. Iram S, Hayat M, Tahir M, Gul A, Abdullah Al. Chloroplast genome sequence of Artemisia scoparia: comparative analyses and screening of mutational hotspots. Plants (Basel). 2019:8:476.

41. Shen Q, Zhang L, Liao Z, Wang S, Yan T, Shi P, Liu M, Fu X, Pan Q, Wang Y, et al. The genome of Artemisia annua provides insight into the evolution of Asteraceae family and artemisinin biosynthesis. Mol Plant. 2018;11:776-88.

42. Kim K, Choi K, Jansen R. Two chloroplast DNA inversions originated simultaneously during the early evolution of the sunflower family (Asteraceae). Mol Biol Evol. 2005;22:1783-92.

43. Yang Z, Nielsen R. Estimating synonymous and nonsynonymous substitution rates under realistic evolutionary models. Mol Biol Evol. 2000;17:32-43.
44. Shahzadi I, Abdullah MF, Ali Z, Ahmed I, Mirza B. Chloroplast genome sequences of Artemisia maritima and Artemisia absinthium: comparative analyses, mutational hotspots in genus Artemisia and phylogeny in family Asteraceae. Genomics. 2020;112:1454-63.

45. Malik S, Vitales D, Hayat M, Korobkov A, Garnatje T, Vallès J. Phylogeny and biogeography of Artemisia subgenus Seriphidium (Asteraceae: anthemideae). Taxon. 2017;66:934-52

46. Park M, Chung G. A taxonomic review of Artemisia sect. Absinthium in Korea. Korean J PI Taxon. 2013:43:188-95.

47. Bremer K. Tribal interrelationships of the Asteraceae. Cladistics. 1987;3:210-53.

48. Panero J, Freire S, Ariza Espinar L, Crozier B, Barboza G, Cantero J. Resolution of deep nodes yields an improved backbone phylogeny and a new basal lineage to study early evolution of Asteraceae. Mol Phylogenet Evol. 2014; 80:43-53.

49. Funk V, Susanna A, Stuessy T, Bayer R. Systematics, evolution, and biogeography of Compositae: American Society of Plant Taxonomists; 2009.

50. Doh E, Paek S-H, Lee G, Lee M-Y, Oh S-E. Application of partial internal transcribed spacer sequences for the discrimination of Artemisia capillaris from other Artemisia species. Evid-Based Compl Alt. 2016;2016: 7043436.

51. Garcia S, McArthur E, Pellicer J, Sanderson S, Vallès J, Garnatje T. A molecular phylogenetic approach to western North America endemic Artemisia and allies (Asteraceae): untangling the sagebrushes. Am J Bot. 2011;98:638-53.

52. Song M, Li J, Xiong C, Liu H, Liang J. Applying high-resolution melting (HRM) technology to identify five commonly used Artemisia species. Sci Rep. 2016;6:34133.

53. Pang $X$, Liu C, Shi L, Liu R, Liang D, Li H, Cherny S, Chen S. Utility of the trnH-psbA intergenic spacer region and its combinations as plant DNA barcodes: a meta-analysis. PLoS One. 2012;7:e48833.

54. Kode V, Mudd E, lamtham S, Day A. The tobacco plastid accD gene is essential and is required for leaf development. Plant J. 2005;44:237-44.

55. de Vries J, Sousa F, Bölter B, Soll J, Gould S. YCF1: a green TIC? Plant Cell. 2015;27:1827-33.

56. Rousseau-Gueutin M, Huang X, Higginson E, Ayliffe M, Day A, Timmis J. Potential functional replacement of the plastidic acetyl-CoA carboxylase subunit $(a c c D)$ gene by recent transfers to the nucleus in some angiosperm lineages. Plant Physiol. 2013;161:1918-29.

57. Park S, Ruhlman T, Weng M-L, Hajrah N, Sabir J, Jansen R. Contrasting patterns of nucleotide substitution rates provide insight into dynamic evolution of plastid and mitochondrial genomes of Geranium. Genome Biol Evol. 2017:9:1766-80.

58. Thode V, Lohmann L. Comparative chloroplast genomics at low taxonomic levels: a case study using Amphilophium (Bignonieae, Bignoniaceae). Front Plant Sci. 2019;10:796.

59. de Vries J, Archibald J, Gould S. The carboxy terminus of YCF1 contains a motif conserved throughout >500 Myr of Streptophyte evolution. Genome Biol Evol. 2017:9:473-9.

60. Roje D. Evaluating the effects of non-neutral molecular markers on phylogeny inference. PLoS One. 2014;9:e87428.

61. Mandel J, Dikow R, Funk V. Using phylogenomics to resolve mega-families: an example from Compositae. J Syst Evol. 2015;53:391-402.

62. Mandel J, Dikow R, Siniscalchi C, Thapa R, Watson L, Funk V. A fully resolved backbone phylogeny reveals numerous dispersals and explosive diversifications throughout the history of Asteraceae. Proc Natl Acad Sci U S A. $2019 ; 116: 14083-8$

63. Doyle J, Doyle J. A rapid DNA isolation procedure for small quantities of leaf tissue. Phytochem Bull. 1987;19:11-5.

64. Dierckxsens N, Mardulyn P, Smits G. NOVOPlasty: de novo assembly of organelle genomes from whole genome data. Nucleic Acids Res. 2017;45:e18.

65. Geneious Prime. https://www.geneious.com. Accessed 1 July 2019.

66. Lowe TM, Chan PP. tRNAscan-SE On-line: integrating search and context for analysis of transfer RNA genes. Nucleic Acids Res. 2016:44(Web Server issue): W54-7.

67. Lohse M, Drechsel O, Bock R. OrganellarGenomeDRAW (OGDRAW): a tool for the easy generation of high-quality custom graphical maps of plastid and mitochondrial genomes. Curr Genet. 2007:52:267-74.

68. Katoh K, Standley D. MAFFT multiple sequence alignment software version 7: improvements in performance and usability. Mol Biol Evol. 2013;30:772-80.

69. Edgar R. MUSCLE: multiple sequence alignment with high accuracy and high throughput. Nucleic Acids Res. 2004;32:1792-7. 
70. Rozas J, AF-M, Sánchez-DelBarrio J, Guirao-Rico S, Librado P, Ramos-Onsins S, Sánchez-Gracia A. DnaSP 6: DNA sequence polymorphism analysis of large data sets. Mol Biol Evol. 2017;34:3299-302.

71. Yang Z. PAML 4: phylogenetic analysis by maximum likelihood. Mol Biol Evol. 2007;24:1586-91.

72. Gao F, Chen C, Arab D, Du Z, He Y, Ho S. EasyCodeML: a visual tool for analysis of selection using CodeML. Ecol Evol. 2019;9:3891-8.

73. Stamatakis A. RAxML version 8: a tool for phylogenetic analysis and postanalysis of large phylogenies. Bioinformatics. 2014;30:1312-3.

74. Huelsenbeck J, Ronquist F. MRBAYES: Bayesian inference of phylogenetic trees. Bioinformatics. 2001;17:754-5.

75. Lanfear R, Frandsen P, Wright A, Senfeld T, Calcott B. PartitionFinder 2: new methods for selecting partitioned models of evolution for molecular and morphological phylogenetic analyses. Mol Biol Evol. 2017;34:772-3.

76. Darriba D, Posada D, Kozlov A, Stamatakis A, Morel B, Flouri T. ModelTestNG: a new and scalable tool for the selection of DNA and protein evolutionary models. Mol Biol Evol. 2020;37:291-4.

77. Rambaut A, Drummond A, Xie D, Baele G, Suchard M. Posterior summarization in Bayesian phylogenetics using tracer 1.7. Syst Biol. 2018;67:901-4.

78. Kumar S, Stecher G, Tamura K. MEGA7: molecular evolutionary genetics analysis version 7.0 for bigger datasets. Mol Biol Evol. 2016;33:1870-4.

79. Kalendar R, Lee $D$, Schulman A. Java web tools for PCR, in silico PCR, and oligonucleotide assembly and analysis. Genomics. 2011;98:137-44.

\section{Publisher's Note}

Springer Nature remains neutral with regard to jurisdictional claims in published maps and institutional affiliations.

Ready to submit your research? Choose BMC and benefit from:

- fast, convenient online submission

- thorough peer review by experienced researchers in your field

- rapid publication on acceptance

- support for research data, including large and complex data types

- gold Open Access which fosters wider collaboration and increased citations

- maximum visibility for your research: over $100 \mathrm{M}$ website views per year

At $\mathrm{BMC}$, research is always in progress.

Learn more biomedcentral.com/submissions 